\title{
La idea de Dios en niños, adolescentes y jóvenes. La dimensión cognoscitiva
}

Bernhard Grom

\section{Resumen}

Este texto del renombrado profesor Bernhard Grom aborda la cuestión de qué procesos psicológicos son esenciales para el aprendizaje, la educación y la socialización, con cuestiones de educación religiosa, es decir, la cuestión de cómo se aprende la religión. No sólo los contextos escolares desempeñan un papel, sino todos los ámbitos en los que se puede encontrar la religión.

\section{Palabras clave}

Psicología, conocimiento, infancia, aprendizaje, religión.

El texto que sigue se refiere a lo que es la cuestión fundamental y el núcleo incuestionable de la Pedagogía cristiana de la Religión: la fe en Dios. ¿Cuál es su origen y desarrollo, y cómo podemos promover su evolución, a fin de que una fe así vaya avanzando hacia su integración personal, sea sanamente equilibrada, consciente asimismo de su responsabilidad y capaz de sobreponerse a dificultades? Nos referimos naturalmente a una fe que refuerce la autoestima, se exprese en agradecimiento y adoración, sea prosocialmente activa y presente, al mismo tiempo, un nivel aceptable de reflexión: una fe,

1 Profesor emérito de Educación Religiosa y Psicología de la Religión en la Escuela Superior de Filosofía de Múnich. El texto es la traducción de la primera parte del capítulo cuatro de su obra en alemán: B. Grom, Religionspädagogische Psychologie des Kleinkind-, Schul- und Jugendalters, Patmos Verlag, Düsseldorf 2000, 5 ed. [Psicopedagogía religiosa de la edad infantil, escolar y juvenil]. La traducción se debe a Mikel Amas Etxaniz. 
por último, que esté implementando gradualmente el objetivo ineludible de nuestra visión psicopedagógica al respecto.

Los estudios pertinentes al tema, tanto a nivel de Psicología evolutiva como de Psicología de lo religioso, han tratado esta cuestión desde diversos puntos de vista y valiéndose de conceptos distintos. Así, por ejemplo, hablan de la representación de Dios, de la imagen de Dios, de la idea de Dios, del concepto de Dios, de la relación con Dios o de los sentimientos en torno a él, bien sea en lo pertinente al modo y manera como buscamos ayuda y apoyo por parte de Dios, o bien en lo que atañe a nuestros convencimientos en referencia a él ${ }^{2}$. En todo ello, algunas de estas denominaciones presentan un significado similar, otras, sin embargo, no. En las siguientes líneas habremos de iluminar las cuestiones pedagógica y psicológicamente relevantes de la fe en Dios, comenzando por la perspectiva preferentemente cognitiva y siguiendo con la consideración mayormente emocional.

Esta diferenciación no significa necesariamente una separación de ámbitos, sino que pretende ajustarse a la siguiente concepción: procesos cognitivos (valoraciones de una situación o de la propia persona que desencadenan miedo, confianza o alegría; estrategias de superación; planes trazados; consecuencias de los mismos) están siempre en una muy estrecha relación con lo vivencial (con estados emocionales subjetivos tales como el miedo, la tristeza, el gozo y demás). En el caso que nos ocupa, los sentimientos religiosos se caracterizan precisamente por su componente cognitivo, por su efecto anímico a la hora de pensar en una realidad supra-humana o por el sentirse impresionados por ella. Las emociones son, en todo caso, patrones de reacción, que vienen constituidos esencialmente por estos dos

2 Cf. R. L. Gorsuch, "The conceptualization of God as seen in adjective ratings", Journal of the Scientific Study of Religion 7 (1968) 56-64; K. E. Hyde, Religion in childhood and adolescence. A comprensive review of the research, Birmingham 1990; B. Grom, Religionspädagogische Psycologie des Kleinkind, -Schul-un Jugend-alters, Düsseldorf 1992, 4 ed., 150-219; K. Petersen, Persönliche Gottesvorstellungen. Empirische Untersuchungen Entwicklung eines Klärungsverfahrens, Hamburg 1993; K. Tamminen, Religiöse Entwicklung in Kindheit und Jugend, Frankfurt 1993; R. T. Lawrence, "Measuring the image of God: The God Image Inventory and the God Image Scales", Journal of Psychology and Theology 25 (1997) 214-226. 
componentes, cognición y vivencia (como por una determinada actividad de expresión y conducta, y sus fenómenos concomitantes de tipo fisiológico). Por otra parte, los pensamientos pueden afectar con mayor o menor intensidad lo vivencial de una persona (así como las disposiciones específicas que son importantes para ello: los motivos), llegando incluso a contraponerse a las vivencias ("mis pensamientos sobre Dios me dicen tal cosa, pero mis sentimientos...”). Ello significa: emoción y cognición constituyen subsistemas relativamente autónomos de la personalidad ${ }^{3}$, que han de ser considerados en su actuación recíproca y según su propia identidad.

Una teoría envolvente y ampliamente reconocida en torno a la evolución, cognitiva y emocional de la fe en Dios, no se ha establecido aún ${ }^{4}$. Ello no se debe exclusivamente a los diferentes planteamientos a que hemos aludido, de los que partieron las investigaciones realizadas hasta el momento, sino que es también tributario de la profusa variabilidad de aspectos en los que se desarrolla la fe en Dios, bien sea por influjos de heterosocialización o bien desde el acento puesto en la socialización de la que se es sujeto (autosocialización). Si la investigación en torno al concepto de Dios ha cosechado hasta ahora resultados no muy unitarios, ello puede deberse también al hecho de que las representaciones de Dios en muchos jóvenes son fragmentarias y nada nítidas. Baterías de preguntas sistemáticamente formuladas y pensadas en el marco de la tradición investigadora del estructuralismo genético transmiten fácilmente la impresión de que niños y jóvenes construyen ininterrumpidamente un sistema filosófico coherente. Por otra parte, cuando se valoran sus expresiones espontáneas en torno al tema "Dios", resulta difícil reconocer concepciones que presenten alguna coherencia o líneas evolutivas claras". "Las más de las representaciones en torno a Dios son, en la

3 C. E. Izard, Die Emotionen des Menschen, Weinheim 1981

4 Cf. Hyde, "Religion in childhood and adolescence"; K. H. Reich, "Cognitive-development approaches to religiousness: Which version for which purpose?", The International Journal for the Psychology of Religion 3 (1993) 145-171, D.M. Wulff, "On the origins and goals of religious development", The International Journal of Psychologie of Religion 3 (1993) 181-186; R. W. Hood -B. Spilka -B. Hunsberger - R. Gorsuch, The psychology of religion. An empirical approach, New York 1996, 64.

5 J. P. Deconchy, Structure genetique de l'idee de Dieu chez des catholiqus francais, garçons et filels de 8 a 16 ans, Lumen Vitae, Bruxelles 1967; J. Janssen-J. De Hart-M. 
mayoría de los jóvenes, imprecisas y vagas: que Dios es invisible, que está en nosotros, que no podemos hacernos dueños de él y tenerle bajo control...La variación respecto a las representaciones de Dios es muy amplia". Ningún rasgo, por tanto, que permita percibir algo así como una estructura.

¿Será esto una muestra de la "religiosidad construida a base de retazos típica de nuestra Modernidad tardía? Con todo, la situación no era muy distinta en la época de una religiosidad sociológicamente extendida. Así lo indicaba, al menos, Ross ${ }^{7}$ como resultado de su encuesta a 2000 miembros de organizaciones religiosas entre los 18 y los 29 años: La mayoría de ellos "sólo lo pueden describir (a Dios) con palabras que aprendieron hace no pocos años en la escuela dominical, y sus 'convencimientos de fe' están llenos de dudas e inseguridades, sin que intenten solucionarlas de alguna manera”. A pesar de las dificultades nombradas vemos posible configurar, mediante pequeñas piedras de mosaico, un cierto cuadro, no sin huecos, pero con algunas indicaciones valiosas para la práctica.

¿Desde qué puntos de partida y en qué edad es posible estimular la aparición de brotes iniciales de una comprensión de Dios tal, que se apoye en una visión infantil auténtica y no sea por parte de niños una mera repetición, que difícilmente podrían entender y a lo sumo lo interpretarían indebidamente, en el sentido de un verbalismo o sincretismo verbal?

Y añadiendo otra pregunta al respecto: ¿Qué factores cognitivos, condicionados naturalmente por la evolución, y qué influjos de socialización pueden contribuir (positiva o negativamente) a un desarrollo posterior de este entendimiento de Dios?

Gerardts, "Images of God in adolescence", The International Journal of the Psychology of Religion 4 (1994) 105-121; D. Hutsebaut, Een zekere onzekerheid. Jongeren en geloof, Löwen 1995.

6 H. Beile, Religiöse Emotionen und religiöses Urteil. Ein Empirische Studie über Religiosität bei Jugendlichen, Ostfildern 1998, 128.

7 M. G. Ross, Religious beliefs of youth, New York 1950, 143. 


\section{Primeros brotes de una idea de Dios acorde con la fase infantil}

La pregunta por los primeros indicios se plantea a toda Educación Religiosa Infantil que pretenda respetar la capacidad de entendimiento metafísico en niños, sin forzarla ni minusvalorarla. La cuestión se hace también relevante a la hora de entender más tarde el pensamiento religioso del niño en los años de la Educación Primaria y de impulsarlo por encima de esta fase. Con el fin de presentar previamente el resultado en forma de tesis podríamos decir:

Teniendo en cuenta el pensamiento causal del niño - sus propias indagaciones de orden filosófico-natural y cosmológico, por así decirlo - cabe afirmar que un acompañamiento religioso algo cuidado y en estrecha conexión con la pregunta sobre los orígenes (¿de dónde viene esto?), pueda ya estimular, en niños de 3 años y medio a 4 y medio, las primeras intuiciones de un entendimiento metafísico genuino en torno al Dios creador.

Las estimulaciones a que nos referimos pueden muy bien estar presentes en otras indicaciones emocionalmente significativas sobre el Dios, que nos da la vida, para quien somos sumamente valiosos, que es digno de nuestro respeto por encima de todo lo demás y que nos llama a amar junto con él a todas las demás personas. Estas indicaciones pueden ser asimismo expresadas en diferentes metáforas sobre Dios. Los recuerdos religiosos de la propia infancia que presentaremos en la segunda parte de este capítulo (y por encima de ello, también $\mathrm{Grom}^{8}$ ) muestran claros ejemplos, en los que niños de Educación Infantil y en las edades a las que hemos aludido, asumen con cierta naturalidad un hablar de Dios como de Alguien que ha hecho el mundo, las personas y al niño, y que por todo ello nos ama. La pregunta en torno al origen (¿de dónde viene esto?) constituye una base importante para este primer entendimiento. Este hecho viene avalado por las siguientes observaciones.

8 Grom, Religionspädagogische, 49-104. 
Los esquemas cognitivos de causalidad que el niño pone en marcha al término de la fase sensorial-motora (según Piaget después de los 2 años), le ayudan a entender que su propio actuar es dependiente de otros centros autónomos de actuación, es decir, de otras cosas y de otras personas. De este modo, se despierta su interés por lo que supone un origen, el "de dónde "de las cosas y de los acontecimientos. Piaget ${ }^{9}$ afirma que el niño pregunta, en primer lugar, por su propio origen (su nacimiento), después por el origen de los padres y de las personas en general, y sólo más tarde, por el origen de las cosas. De ello puede ser ilustrativa la siguiente lista de preguntas, formuladas todas ellas por un mismo niño.

\section{Ejemplo:}

- Con 2 años y 3 meses: “¿De dónde vienen los huevos?”; y a continuación, una vez que hubo recibido respuesta: "Y ¿qué ponen las mamás?"

- Con 2 años y 6 meses: “Papá, ¿había personas antes de nosotros?”- Sí.

• “¿Y de dónde han venido?”- Han nacido igual que nosotros.

- “¿Había tierra antes de que tuviera a los hombres encima?”- Sí.

- "¿Y cómo o de dónde ha venido esta tierra si es que no había hombres para hacerla?";

- Con 3 años y 7 meses: “¿Quién ha hecho la tierra? ¿Ha habido un tiempo en el que no estábamos en la tierra?";

- Con 4 años y 5 meses: "Antes de la primera mamá ¿hubo otra mamá?”;

- Con 4 años y 9 meses; “¿Cómo ha venido el primer hombre sin una mamá?”. Igualmente en la misma edad: “Cómo se ha hecho el agua?; y ¿de qué han sido hechas las rocas?”"

En opinión de Piaget, las primeras preguntas sobre el “¿por qué?” hay que entenderlas en el marco de las búsquedas preoperatorias por las causas, indagaciones del niño que hasta la edad de 7/8 años transcurren aún de una manera global y "precausal”. En estas preguntas por el "por qué", el niño mezcla aún la cuestión de las causas en un sentido psicológico (como motivo), en un sentido funcional y "finalístico" (como finalidad) y en un sentido mecánico-biofísico (en

9 J. Piaget, Das Weltbild des Kindes, Stuttgart 1978, 289.

10 Piaget, Das Weltbild des Kindes, 289. 
calidad de "cómo"). El niño las contesta preferentemente con una representación artificialista de un hacer humano: “Quién ha hecho esto?” “Cómo se hace...?” “¿Dónde me habéis encargado?”.

Las primeras preguntas en torno al "por qué" y sus respuestas de índole artificialista contienen ya, de una manera global e indiferenciada, unas primeras intuiciones- lo cual significa "representaciones algo estructuradas", como las que son propias del pensamiento de niños desde los 4 a los 6/7 años - a la hora de entender infantilmente conexiones funcionales y bio-físicocausales. Por encima de ello, contienen además una primera intuición global en torno a una dependencia y a una causalidad totales, y de ese modo, una primera aproximación intuitiva a un Origen por encima de lo humano y por encima del mundo(metafísico), por así decirlo.

Y es que - en la línea de las preguntas sobre el "de dónde" y contando con un saber creciente de su propia dependencia con respecto a sus padres - el niño capta en primer término su propio haber nacido y haber sido traído a la vida como una fundamental dependencia con respecto de sus padres y llega a sospechar el que esto mismo tiene también lugar en los otros seres (de ahí sus elucubraciones de orden sincretista: "el sol ha nacido, ya que también nosotros nacemos" o "las estrellas crecen" como los niños, pero - en su caso de piedrecillas muy pequeñas). En la misma línea el niño pregunta también, una y otra vez, por el origen y el "de dónde" de sus padres, y se familiariza así con la cadena de las generaciones. Su conocimiento con todo va más allá. Las preguntas que ahora siguen en torno al "de dónde", se dirigen por una parte al material primigenio del que crecen las personas. De este modo, un niño de 5-6 años pregunta: “¿qué es uno antes de haber nacido?”, y sospecha: "una hormiga, una burbuja de aire, un trocito de tierra" ${ }^{11}$.

Por otra parte, sus preguntas indagan también en dirección a un "de dónde", tras el cual - visto primero temporalmente - no hay ningún otro “dde dónde?” y constituye así el origen de las personas, de la vida y del mundo ${ }^{12}$.

11 J. Piaget, Nachahmung, Spiel und Traum, Stuttgart 1969, 313.

12 W. Stern, Psychologie der frühen Kindheit, Darmstadt 1965, 353. 
La cuestión planteada en los siguientes ejemplos en torno a cómo el primer hombre haya venido sin mamá o cómo haya podido ser hecha la tierra sin que la haya hecho alguien humano, adquiere únicamente una posible respuesta mediante el recurso último a una evolución del cosmos y de la vida (cuya constitución se halla necesitada de su aclaración) o a una causa última que hace posible su comienzo y su continuación.

Ejemplos:

Hilde, una niña de 4 años y 2 meses:

- ¿Quién era la que estaba conmigo cuando mi madre era pequeña?

- La madre: Hilde no estaba aún; cuando yo era pequeña, estaba con mi madre, con tu abuela.

- ¿Y quién estaba con la abuela, cuando era pequeña?

- La bisabuela.

- Y quien estaba con todas las madres? ${ }^{\text {3. }}$.

Una niña de la misma edad:

- ¿Cómo se hacen las mujeres?

- ¿Por qué?

- Porque la carne está ahí.

- ¿En qué mujeres estás pensando?

- En ti y en otras mujeres.

- Eso no lo sé.

- Yo creo que las hace el carnicero. ¿No te parece?

Casi en la misma edad, la niña preguntaba:

- ¿Quién ha hecho los pájaros?

Ocho meses más tarde, con 4 años y 10 meses:

- ¿Quién ha hecho la tiza?

- La tiza no la ha hecho nadie, la encontramos por ahí.

- Sí, pero ¿de dónde viene, quien la ha hecho?

13 Stern, Psychologie der frühen Kindheit, 354. 
Y cuatro días más tarde:

- ¿Cómo se hacen los hombres?

- Las personas crecen de sus madres.

- Sí, pero... ¿y las personas adultas?

- Todas ellas han sido alguna vez pequeñas.

- Sí, pero de dónde, antes de que hubiera algo, ¿cómo se han hecho los hombres? ${ }^{14}$

Una niña de 4 años:

- Siempre comienza con los niños, mamá, pero ¿cómo es eso posible? ¿Quién ha cuidado de que hubiera los primeros niños?

Un niño de 5 años, con mucha seriedad y dirigiéndose a su madre: - ¿Qué había entonces antes de nosotros? ¿de nuestra familia? Y ¿antes de que hubiera personas?

Si a niños de esta edad se les responde aludiendo a Dios, el creador y hacedor de todas las cosas y de las personas, ellos vuelven a preguntar a menudo e insistentemente en la dirección indicada: "Y ¿quién ha hecho a Dios?" O si no: "Pero, ¿qué había antes que Dios?” Así una niña de 6 años: "Mamá, iquién ha hecho a Dios? Esto no lo entiendo. ¿Él no puede hacerse a sí mismo? Sí que puedo decir: algún hombre ha hecho a Dios, pero me quedo ahí, porque me viene de nuevo la pregunta ¿y quién ha hecho a ese hombre?”'s.

Esto muestra que la actividad creadora de Dios es imaginada por el niño totalmente según el modelo de un hacer humano consistente en elaborar o trabajar un material que previamente está ahí - y precisamente este modo de entender es el que no da una respuesta satisfactoria a la pregunta que él tiene por el origen. Y es que lo que su indagación busca supuestamente es algo así como una explicación causal metafísica, que se ajuste a su propio asombro ante la

14 V. Rasmussen, Ruth. Tagebuch über Entwicklung eines Mädchens von der Gerburt bis zum 18, München 1934.

15 J. Klink, Kind und Leben, Düsseldorf 1972, 39. 
vida que - en último término - da la impresión de ser buena, y que no la hacen las personas mismas, sino que, a lo más, la configuran y la pueden transmitir. Junto al resto de formas de causalidad, el niño - en sus preguntas en torno al origen - puede, por tanto, llegar a atisbar una suerte de hacer (o entender, en torno a ello, algunas indicaciones), que de algún modo va más allá de un hacer meramente humano o de un actuar exclusivamente biofísico. A menudo utilizará para ello palabras como "dejar" o "permitir", que llevan consigo la causalidad que es propia de las cosas y de las personas de su entorno y así dirá que Dios "permite" que las nubes den su lluvia, que las plantas crezcan, que los hombres trabajen, etc...

Pero sólo cuando el niño corrige ("acomoda", en sentido de Piaget) la representación artificialista de un hacer similar al humano y al de sus padres, y construye en su lugar el concepto "análogo" de un actuar por encima de lo humano, al que en último término se debe todo hacer y crecer de las personas y del mundo (de modo, además, que un actuar tal no es tributario de algo inmediatamente anterior)... sólo entonces encuentran respuesta satisfactoria sus preguntas por el origen y por el "de dónde" de las persona, animales y cosas de su percepción.

A un niño de 5 años, al que se le había contado previamente y de forma reducida el relato bíblico de la creación, una historia tal le pareció tan sorprendente, que le llevó a decir: "Qué fuerte que el buen Dios sea capaz de hacerse a sí mismo"16. De este modo el asombro del niño muestra probablemente que con la expresión "hacerse a sí mismo/ crearse", quería expresar otra cosa que - como es habitual en otros niños - designa un simple "crecer".

Un entender a Dios del modo como acabamos de exponerlo, es cognitivamente y desde el punto de vista de filosofía de la naturaleza - la respuesta a la pregunta por el origen último del cosmos y de la persona. Desde una perspectiva emocional y de filosofía de los valores, esta visión se completa con la cuestión en torno al valor supremo y al fundamento último, capaz de sustentar una aceptación

16 Stern, Psychologie der frühen Kindheit, 354. 
incondicional del valor de la propia persona, de los demás y de la vida en general, y que merece un entendimiento de Dios como el de un ser, que de modo eminente, merece nuestra confianza, nuestra alabanza y nuestra colaboración - o nuestra "co-dilección”.

Los primeros inicios posibles de un entendimiento de Dios que se ajuste a la tierna infancia presentan las siguientes características, que en gran parte se corresponden con los rasgos fundamentales del pensamiento pre operatorio del niño entre 4 y 6/7 años, y han sido descritos por Piaget.

Con gran probabilidad, el entendimiento de Dios, en sus comienzos...

- Se va adquiriendo mediante una repetición algo entendida (en forma de reconstrucción o asimilación pasiva) y un inicial asentimiento; sin que medie, por parte del niño, una formulación propia ni un descubrimiento;

- Se va constituyendo mediante un primer entendimiento aún no reflexionado; que no puede aún estar a la altura de una confrontación con otros modos alternativos de entender a Dios o con dificultades, ni responde a comprobaciones críticas según reglas de lógica formal;

- Oscila entre el mundo de la fantasía infantil y el mundo real, y presenta aún - desde una perspectiva adulta - un cierto carácter de cuento.Aunque el niño, ya con 2/3 años, va distinguiendo con mayor claridad el mundo de lo observado a su alrededor y el mundo de lo deseado y vivido en su fantasía, en sus fabulaciones y en sus juegos, así y todo, mantiene ambos ámbitos como igualmente reales hasta aproximadamente los 7/8 años, e incluso olvida el nivel de la realidad cuando vive sumido en la esfera de su fantasía. (Y puede, por ello, fluctuar de un lado a otro entre representaciones contradictorias) Solo a partir de esa edad será capaz de subordinar con claridad lo meramente imaginado bajo la preponderancia de lo real, que es lo observado o que se da a conocer necesario para el pensamiento ${ }^{17}$.

17 J. Piaget, Urteil und Denkprozeb des Kindes, Düsseldorf 1972, 240-247. 
- Oscila igualmente entre concepciones masivamente antropomorfas y primeras ideas de una trascendencia consciente. Pero esto último, a modo de intuición global, es decir, en "percepciones ordenadas", las cuales capacitan ciertamente para operaciones tales como el clasificar y el comparar, pero que todavía están muy unidas a la observación (a lo concreto), son poco precisas y tienden a aclaraciones "precausales" de los fenómenos naturales y del actuar y ser de Dios. En pocas palabras: muestran tendencia a visiones antropomorfas, coincidentes con lo humano y en especial, a sus padres.

\section{Desarrollo y promoción de la idea de Dios más allá de las primeras aproximaciones}

¿Cómo puede evolucionar el entendimiento de Dios tras la constitución de sus planteamientos iniciales, y de qué factores depende tal desarrollo? Investigaciones empíricas que pudieran contribuir a responder a esta pregunta han sido realizadas teniendo en cuenta mayormente el concepto de antropomorfismo. Su tratamiento ha sido incluso poco sistemático y sus resultados no muy fáciles de clasificar. En cuanto a su punto de partida teórico, las más serias se han apoyado en los estadios de evolución cognitiva según Piaget.

\subsection{Antropomorfismo. ¿Literal y/o simbólico analógico?}

En sentido de las Ciencias Religiosas, los antropomorfismos (de ánthropos: hombre y morphé: forma, figura) son figuraciones y afirmaciones que representan a los dioses o a Dios con propiedades humanas. Antropomorfismos físicos describen a Dios (o a los dioses) atribuyéndole propiedades humanas corporales, tales como barba, ojos, nariz, manos y orejas (junto a ello la Historia de las Religiones conoce igualmente el así llamado Teriomorfismo, por su utilización de representaciones en forma de animales); los antropomorfismos psíquicos (antropopatismos), por su parte, reconocen en lo divino únicamente fenómenos y reacciones humano-anímicas, tales como el querer, amar, tener misericordia, reír, la ira o el arrepentimiento ${ }^{18}$.

18 G. Van der Leeuw, Phänomenologie der Religion, Tübingen 1956. 
Con todo y para una interpretación psicoevolutiva (así como para la consideración pedagógico-religiosa), resulta más relevante otra distinción, que analiza representaciones y afirmaciones antropomorfas bajo el aspecto de si albergan en su intención algo así como una "conciencia de transcendencia", es decir, si de alguna manera sobrepasan una determinada dimensión que sólo corresponde a las personas, como lo es su materialidad, su temporalidad, su limitación, su determinación por parte de otros, su debilidad de carácter y otros rasgos similares. Es legítimo afirma que tanto los antropomorfismos físicos como también los psíquicos pueden ser entendidos y utilizados de una manera "literal" o bien de un modo "simbólico-analógico".

La distinción a que aludimos se encuentra ya en la Biblia. Así, los profetas de Israel polemizan contra los "ídolos" fútiles de los pueblos de alrededor y llaman al reconocimiento y la adoración de Yahve, a quien nadie puede ver (Is 45,15; 1 Tim 6, 16; 1 Jn 4,12), de quien no puede ser hecha figura alguna (Dn 4,15) y que - en calidad de creador - se diferencia radicalmente de los hombres, con lo que se pone freno a todo antropomorfismo literal, que supondría una representación impropia de Dios.

Por otra parte, los textos bíblicos y los salmos en especial, no son nada timoratos a la hora de referirse al rostro de Dios, a su mano poderosa, a su estar dormido y despertar (salmo 44, 24; 78, 65), a su recelo y a su ira, y utilizan metáforas como la de un "rey" y un "pastor", sin atribuirle por ello una corporeidad, su masculinidad o su femineidad - entendiendo, por tanto, tales afirmaciones como claramente conscientes de su intención de transcendencia, en un sentido análogo y simbólico. (Al igual que Imanuel Kant - tanto en su obra La Religión en los límites de la razón pura como en sus Prolegómenos- condena el antropomorfismo "objetivo" y "dogmático", pero reconoce el "simbólico" y "análogo" como indispensable para la razón, en la medida en que es utilizado como medio y camino para un conocimiento más adecuado). En efecto, la fe en que el Dios vivo se dirige a la persona y busca entablar una relación vital con ella, no puede ser expresada de otro modo: "El antropomorfismo físico es superable aunque nunca lo será totalmente; el antropomorfis- 
mo psíquico, por su parte, es consustancial a la capacidad humana de representación y de pensamiento. Quien quisiera abandonarlo y prescindir del mismo, no tendría otra opción que el mutismo en referencia a Dios" ${ }^{19}$. Posiblemente no sean solo los niños sino también los mayores, quienes en un primer momento entienden e interpretan (de forma intuitiva) cada causa eficiente desconocida como similar a la dimensión humana, pues de otro modo les resultaría absolutamente inasequible; sólo más tarde logran desarrollar un entendimiento más adecuado de esa misma realidad merced a informaciones correctivas (acomodativas) y a ulteriores experiencias y reflexiones. De este modo se entiende que personas adultas, junto con un concepto teológicamente correcto, utilizan también en su vida cotidiana un concepto de Dios no reflexionado y tendencialmente antropomorfo ${ }^{20}$.

Es importante observar qué niños tienen (o al menos expresan) un entendimiento de Dios que aglutina al mismo tiempo elementos literales, así como de conciencia de trascendencia, análogos y antropomorfos. Ya Clavier (1926) en su investigación clásica sobre alumnos y alumnas evangélicos entre los 6 y los 12 años que visitan los oficios dominicales, había detectado en sus respuestas a la pregunta sobre quién es Dios y donde está Dios tres formas distintas de antropomorfismo infantil, de las que presentamos aquí dos pruebas por cada una de ellas:

Antropomorfismo totalmente material: "Él (Dios) se parece a nosotros, ya que lleva vestidos y recoge flores" (7 años). "Dios está en el cielo; tiene una casa; la casa de Dios es como la nuestra" (9 años).

Antropomorfismo material atenuado: "Dios es el Padre Santo. Dios es un hombre, pero no totalmente como los demás hombres - está sentado en un trono y en torno a él están los ángeles" (10 años). "Dios se encuentra en el cielo. Sí, él tiene una casa, que es el alma. Yo me imagino que es la casa de Dios en el templo" (11 años).

19 Van der Leeuw, Phänomenologie der Religion, 190.

20 J. L. Barrett - F. C. Keil, "Conceptualizing a nonnatural entity: Antropomorphism in God concepts”, Cognitive Psychology 31 (1996) 219-247. 
Antropomorfismo más o menos espiritualizado: "Yo creo que él está al mismo tiempo en todas las casas" (9 años). "Dios es el padre todopoderoso. ¡Dios es el espíritu que se encuentra en nuestra alma!” (1l años).

Las expresiones verbales de niños que van creciendo no pueden ser siempre ordenadas con seguridad siguiendo los parámetros anteriores. Menos aún los dibujos infantiles que representan a Dios, ya que no son interpretables de manera fiable a menos que los niños mismos los aclaren. En las investigaciones, que en este sentido resultan muy significativas, de Harms ${ }^{21}$, Pitts ${ }^{22}$, Bucher ${ }^{23}$ y Hanisch $^{24}$, los adultos han invitado a niños únicamente a dibujar y a pintar, pero no así a explicar sus producciones, lo cual hace casi imposible una evaluación fiable y diferenciada. (Por suerte algunos de los alumnos han comentado libremente sus propios dibujos.).

Y es que, si bien hablan sobre ello o hacen sus dibujos, los niños representan a menudo a Dios con propiedades humanas, pero lo que también piensan es que es más que un hombre.

Las tres fases formas distintas de antropomorfismo, recogidas por Clavier, se muestran en las metáforas lingüísticas y en las figuras dibujadas de la siguiente manera.

- Cuando un niño de 6 años dice: "Dios tiene vestidos blancos y vuela por los alrededores" o "Dios vive en una casa en el cielo y con un telescopio mira a la tierra", su expresión es aún en gran parte antropomorfa y no simbólica; Dios a la manera de una persona especial, alguien misterioso.

21 E. Harms, "The development of religious experience in children", American Journal of Sociology 50 (1944) 112-122.

22 V. P. Pitts, "Drawing the invisible: Children's conceptualization of God", Character Potential 8 (1976), 12-24.

23 A. A. Bucher, "'Gott iste in Mensch für mich,: Kurzbericht über eine empirische Untersuchung zu den Gottesbidern im Grundschulalter", Katechetische Blätter 116 (1991) 331-335.

24 H. Hanisch, Die zeichnerische Entwicklung des Gottesbilds bei Kindern und Jugendlichen. Eine empirische Vergleichsuntersuchung mit religiös und nicht religiös Erzogenen im Alter von 7-16 Jahren. Sttutgart 1996. 
- Cuando un niño de 8 años pinta a Dios con grandes manos y con una barba muy larga y añade que tiene mayores manos que nosotros para poderlo crear todo, y su barba más larga que la de las personas, está mostrando ya una cierta conciencia de transcendencia bien reconocible y comienza a entender su "antropomorfismo físico”, si bien inicialmente, como análogo y simbólico. Como dato significativo cabe resaltar que de los alumnos que Hanisch ${ }^{25}$ invitó a pintar sus representaciones, fueron los niños de 9 a 16 años quienes con más frecuencia pintaron a Dios con barba, más que los del grupo de 7 y 8 años, y consideraron esto como un símbolo de que Dios es incomparablemente más antiguo (eterno) y más sabio que las personas. Y esto, aunque los adolescentes, ya a partir de los 15 años, rechazan con vigor esta representación de Dios.

- La conciencia de transcendencia en el modo de entender a Dios y el carácter simbólico de la imagen y el lenguaje queda bien claro en el caso de una alumna de 11 años, que pinta una nube, de la que sale una mano, y la chica escribe: "Yo he pintado la nube porque para mí Dios no tiene ninguna figura humana; la mano la mantiene sobre la tierra para protegerla". Niños y adolescentes con un entendimiento de Dios claramente consciente de transcendencia echan mano a menudo de imágenes naturales - como la alumna de 12 años que pinta un sol y escribe a modo de comentario: "Dios $=$ sol $=$ claridad, luz calor" ${ }^{26}$.

\subsection{Antropomorfismo: ¿dependiente de la evolución e igualmen- te de la socialización?}

¿Cómo se desarrolla en niños y jóvenes que han sido educados religiosamente la tendencia a representaciones antropomorfas de Dios y su posible apertura a representaciones de Dios conscientes de su transcendencia?

La pregunta no se puede responder en base a resultados de investigación que sean claros y convincentes; el desarrollo religioso y su 25 Hanisch, Die zeichnerische Entwicklung.

26 Hanisch, Die zeichnerische Entwicklung, 70. 
evolución constituyen un campo bien complejo, muy variable y metodológicamente, difícil de investigar.

Clavier ${ }^{27}$ percibió en su reducida prueba una clara reducción de los antropomorfismos masivos entre los 6 y los 12 años, coincidente en el mismo tiempo con un aumento de representaciones antropomorfas más atenuadas y más espirituales. Deconchy ${ }^{28}$ en su estudio de 4660 chicos y chicas entre 8 y 16 años que acreditaban educación religiosa escolar católica, creyó reconocer una evolución patente hacia un lenguaje sobre Dios más consciente de transcendencia, lo que hacía pensar en una idea de Dios correspondiente a ello. Para esto había presentado a sus alumnos una lista de seis palabras, tras las cuales ellos habían de escribir las cinco asociaciones que les surgieran espontáneamente - en referencia, concretamente a los conceptos: casa, padre, madre, Dios, pecado, sacerdote. Las asociaciones recogidas para la palabra "Dios", las sometió a un análisis factorial, analizando igualmente su relación a los otros conceptos. Las observaciones que se obtienen en un procedimiento así son muy dependientes del método utilizado, y no resulta nada fácil deducir de las propiedades semánticas de expresiones de los alumnos, leyes fiables de naturaleza cognitiva y emocional. Por estas razones, esta detallada investigación no ha tenido mucho eco en la discusión pertinente. En cualquier caso, Deconchy extrajo sus consecuencias distinguiendo tres fases diferenciadas:

- En una primera fase de atribución (entre los 8 y 10 años) el niño asume sobre todo (no exclusivamente, por tanto) afirmaciones de la catequesis en torno a Dios, de tal modo que opera con determinados atributos, tales como poderoso, omnipresente, conocedor de todo, dotado de hermosura, santo, justo o misericordioso. En todo ello el niño ve a Dios preferentemente como creador, aunque no todavía en modo integral sino más bien desde determinadas capacidades como pueden ser la fuerza, la hermosura y la bondad. Conviene también tener en cuenta que, sobre todo al comienzo, lo nombra a menudo en conexión con fenómenos naturales de gran poder, anexionándolo a ellos de

27 H. Clavier, L'idee de Dieu chez l'enfant, Paris 1926.

28 Deconchy, "Structure genetique". 
forma aún inmanente, y que cuando lo describe en sus propiedades espirituales ("inteligente", "listo", "muy capaz"), lo hace también en una forma que es análoga a sus propias observaciones referentes a personas de su mundo infantil.

- En la fase de la personalización (entre los 11 a los 13/14 años) Dios se asocia a menudo con conceptos personales, tales como los de maestro, señor, creador, jefe, padre, Cristo-Salvador. Pocas veces es nombrado en conexión con fenómenos naturales (el sol, el cielo, las nubes, la luna), sino que, desde un comienzo, actúa como una persona superior al mundo (en la que los atributos anteriores encuentran su unidad), y de una manera bien diferenciada de las fuerzas de la naturaleza, que ahora son captadas posiblemente con más claridad en su identidad propia y despojadas, por esto mismo, de un supuesto carácter personal. El Dios de esta fase es también caracterizado más claramente como Alguien por encima de lo humano, aunque los niños siguen valiéndose de propiedades humanas para referirse a él. (Así, un niño de 11 años llama a Dios "grande "pero añade a continuación: "no según el cuerpo". E igualmente una niña: "al que no se puede imaginar"). Símbolos tales como la luz aparecen ahora más frecuentemente. Deconchy aclara esta transformación aludiendo a una capacidad de abstracción más desarrollada, que se expresa también en una inclinación a los sustantivos (sabiduría, grandeza, santidad, inteligencia) que ahora, sustituyen a los anteriores adjetivos (sabio, grande, santo, inteligente) y se muestran en expresiones tales como "supremo", "por encima de todo lo demás" y similares, que denotan ya un carácter algo más análogo y consciente.

- En la fase, por fin, de interiorización (a partir de los 14/15), los adolescentes acentúan con más fuerza la trascendencia de Dios y lo descubren más desde dimensiones emocionalmente relevantes, como la confianza, el abandono, la duda, etc. Conceptos tales como el de amigo, camarada, confidente, refugio... aparecen con gran fuerza en primera línea (pero también sentimientos de rechazo). 
En su proyecto con alumnos luteranos finlandeses, a quienes Tamminen ${ }^{29}$ invitó a completar la frase "en mi opinión Dios es ...", el investigador descubrió en general - sin la diferenciación de Clavier - pocas "ideas antropomorfas de Dios", pero detectó (y en contra de lo que esperaba) que estas ideas no se van reduciendo linealmente, sino que son notablemente menos frecuentes entre alumnos de 9/10 años (un 4\%) que en alumnos de 13 a 16 años, quienes acreditan porcentajes de 15,11 y $14 \%$.

El estudio longitudinal de Hutsebaut ${ }^{30}$ con alumnos de los Países Bajos (de 12 a 18 años) no logró descubrir en sus respuestas al impulso "Dios es para mí como..." una línea de evolución que fuera clara, por lo que las representaciones de Dios por parte de estos jóvenes podían atribuirse mayormente a influjos de socialización.

Hanisch ${ }^{31}$, por su parte, en su valoración de 1471 dibujos de alumnos entre los 7 a 16 años, y educados cristianamente, ha podido determinar que, entre las chicas, las representaciones de Dios con rasgos humanos (=antropomorfos) se reducen de modo continuo a partir de los 7/8 años, mientras que en el caso de los chicos van aumentando entre los 8 y los 9 años, y más tarde - con algunas excepciones - van en general reduciéndose. No hay explicación convincente para ello, como tampoco para las observaciones de Tamminen. (Aparte quizá de que el diagnóstico "antropomorfo" haya sido utilizado de una manera no suficientemente diferenciada.) Con todo, resultan interesantes, por otra parte, los datos de Hanisch ${ }^{32}$ en torno a representaciones de Dios simbólicas, es decir, no antropomorfas, en las diferentes fases de edad:

\begin{tabular}{|l|c|c|c|c|c|}
\hline Edad alumnos & $7 / 8$ & $9 / 10$ & $11 / 12$ & $13 / 14$ & $15 / 16$ \\
\hline Imágenes no antropomórficas de Dios & $1.5 \%$ & $20 \%$ & $40.1 \%$ & $56.1 \%$ & $76 \%$ \\
\hline
\end{tabular}

Estas cifras hablan de nuevo a favor de un aumento en continuidad de una representación de Dios más simbólica y más consciente de

29 Tamminen, Religiöse Entwicklung.

30 Hutsebaut, Een zekere onzekerheid, 39-81.

31 Hanisch, Die zeichnerische Entwicklung.

32 Hanisch, Die zeichnerische Entwicklung, 89-93. 
su trascendencia, con un primer salto cuantitativo entre los 9 y 10 y los 11 y 12 años. (Además, las chicas - posiblemente por estar religiosamente más interesadas - muestran más frecuentemente que los chicos una representación simbólica de Dios. En este sentido cabe interpretar también - teniendo en cuenta en cada caso toda una multitud de aspectos - otra serie de estudios en referencia a la evolución del entendimiento de Dios ${ }^{33}$. En la evolución hacia una percepción de Dios con mayor conciencia de trascendencia se perciben diferencias que no solo son específicas de la edad sino también individuales y dependientes de la socialización. Esta evolución depende probablemente de los siguientes tres factores principales.

\subsubsection{La evolución lógico-conceptual, necesaria pero no suficiente}

El aumento de representaciones de Dios con una mayor conciencia de trascendencia y carácter más simbólico, a que nos referíamos, y que va creciendo con la edad - en el caso de alumnos con talento intelectual puede aparecer algo antes que en otros, escolarmente algo rezagados ${ }^{34}$ - muestra un claro paralelismo con la evolución de la competencia conceptual lógica tal como Piaget la había previsto. Una correspondencia de este orden es - al menos en grandes rasgos - bastante clara, aunque los intentos de Hoge y Petrillo ${ }^{35}$ y también de Zachry, por mostrar una relación directa entre entendimiento religioso y nivel de pensamiento formal, solo han logrado detectar dependencias débiles (lo que podría deberse a una infravaloración del pensamiento religioso en el caso del test de Peatling "Thinking about the Bible” utilizado en las preguntas). Así y todo, la correspondencia en cuestión, aunque la siguiente hipótesis habría der ser mejor comprobada y ciertas concreciones investigadas con más

33 J. B. McDowell, The development of the idea of God in the catholic child, Washington 1952; R. Goldman, Religious thinking from childhood to adolescence, London 1964; K. E. Hyde, Religious learning in adolescence, Edinburgh 1965; R. Vianello, La religiosità infantile, Florencia 1976; K. L. Ladd - D. N. McIntosch - B. Spilka, "Children's God concepts: Influences of denomination, age and gender", The International Journal for the Psychology of Religion 8 (1998) 49-56.

34 McDowell, The development of the idea of God.

35 D. R. Hoge - G. H. Petrillo, "Development of religious thinking in adolescence: A test of Goldman's theories", Journal for the Scientific Study of Religion 17 (1978) $139-154$. 
exactitud, puede ser interpretada de la siguiente manera: Los niveles de competencia cognitiva general, investigados por Piaget preferentemente en la dimensión lógica de los ámbitos matemático y de las ciencias naturales, constituyen, si se las considera al menos como "soft structurs", la condición necesaria para un percibir, entender y pensar religiosos más conscientes de trascendencia y más reflexionados: así y todo, este entender y pensar ha de ser promovido mediante estímulos activos de la socialización religiosa.

El pensamiento pre-operatorio (1 a 6 - 6/7 años), con sus conceptos globales (intuiciones), su pensamiento unido a lo concreto, que va procediendo a saltos (de modo sincretista) y se reduce aún a un único punto de vista (centralidad), presentando además una única dirección (irreversibilidad), constituye y brinda la base para una primera visión intuitiva global. Este primer logro se abre a algo así como un origen suprahumano y supramundano - aún no reflexionado y siempre oscilando entre el mundo de la fantasía y el mundo de lo real, así como entre representaciones antropomorfas masivas (materializantes, artificialistas y orientadas a premio y castigo) y otras concepciones incipientes, menos antropomorfas.

El pensamiento operativo-concreto (6/7 - 11/12 años), con sus conceptos más diferenciados y más generales, con su capacidad de clasificación más exacta (en el rango de los valores, por ejemplo), con sus conclusiones que ahora más lógicas, su coordinación de diferentes puntos de vista y su reversibilidad, constituye - a pesar de su reducción a informaciones y tareas concretas - la base para una fundamentación simple de la fe (en este sentido, un alumno de 11 años, seguro de confrontar su posicionamiento con una opinión escuchada, concluyó: "no todo ha podido originarse desde si"). Igualmente constituye la base para una visión conceptualmente más clara en torno al origen último de la vida, más netamente suprahumano y supramundano (un creador), así como para la experiencia ética del sentido y del deber. Y también, con todo lo anterior, para un primer cuestionamiento de concepciones antropomorfas y para una conciencia de trascendencia más depurada. Con todo, este pensar a Dios permanece aún reducido, en gran parte, a consideraciones determinadas y a ámbitos concretos, y no pasa de ser fragmentario. 
El pensamiento formal operativo (a partir de los 11/12 años). Con sus conceptos ya más diferenciados y abarcantes, y su capacidad de llegar a conclusiones que tienen en cuenta puntos de vista diversos, que (de modo muy reversible) resultan ahora controlables según reglas lógicas más universales, brinda por fin (en su aplicación al terreno ético-religioso) la base para una visión reflexionada en torno a un origen entendido claramente en plan transcendente. En su relación a esta visión todas las afirmaciones (Dios "crea", "ve") son entendidas de modo simbólico-analógico como indicaciones en dirección de una realidad que va más allá de la materialidad, de la temporalidad, de la determinación por parte de instancias ajenas y de la limitación.

Una visión de este nivel permite ahora ser aplicada, de forma menos fragmentaria y a modo de principios generales, a experiencias diversas, y ser fundamentada de forma más autónoma y lógica (y no solo a modo de una mera repetición de algo escuchado, sino como una conclusión que partiendo de lo condicionado llega a lo incondicionado, y desde causas constatables asciende una última causa que las sustenta); y permite igualmente, tener en cuenta diversos puntos de vista (así como dificultades y consideraciones alternativas).

Esta visión más reflexionada se obtiene, si se llega realmente a ello, a través de fases de cuestionamiento y duda en torno a una visión infantil de Dios, que asumida con confianza y buena fe, carecía aún de firmeza ante posibles contradicciones.

Lo dicho supone, en referencia a la práctica, que una instrucción cuidada habrá de tener en cuenta los supuestos cognitivos de orden general presentes en los alumnos, con el fin de no exigir por encima de su nivel ni infravalorar las posibilidades reales de sus procesos. Las normas de edad tenidas en cuenta anteriormente tienen solo carácter de indicación.

\subsubsection{Los influjos de la socialización, ¿dificultan o estimulan?}

El desarrollo y la evolución hacia un entendimiento de Dios de mayor conciencia trascendente dependen también de la motivación religiosa (refuerzo externo) así como de la instrucción mediatizada 
por el entorno social. De este modo, niños que han experimentado una educación religiosa regular y cuyos padres participan con mayor frecuencia en la liturgia y - supuestamente - motivan al niño a un comportamiento y a un aprendizaje de carácter religioso, muestran con una frecuencia que es mayor que en otras concepciones no antropomorfas en torno a Dios ${ }^{36}$. El hecho de que un cierto modo de instrucción pueda propiciar un entendimiento de Dios que permita descubrir una mayor conciencia transcendente se desprende de la siguiente observación. En las interviús que Nye y Carlson ${ }^{37}$ llevaron a cabo llama la atención que de los niños de 5 a 8 años, el $30 \%$ de los que habían sido educados en la religión judía, supuestamente bajo el influjo de la prohibición de imágenes, describieron a Dios de modo no antropomorfo, mientras que sus compañeros socializados religiosamente como católicos o protestantes, lo hacían en porcentajes de un 20 o bien un 10\%; por su parte, entre los alumnos de 9 a 16 años, las diferencias entre las descripciones no eran tan considerables. Diferencias similares observó Pitts ${ }^{38}$, cuando invito a niños de 6 a 10 años a dibujar una imagen de Dios.

La presión y la invitación a corregir concepciones religiosas construidas en la infancia (esquemas) y a diferenciarlas (Piaget: realizar su acomodación, su equilibración) es, en el caso de los convencimientos religiosos, notablemente menor que en los ámbitos de la utilización lingüística profana, de las operaciones matemáticas básicas o de las habilidades prácticas. Por esta razón se explica que no pocos adultos desarrollan en su profesión un alto grado de pensamiento formal crítico mientras que sus representaciones religiosas siguen siendo infantiles y rudimentarias. Sorprendentemente, son los jóvenes los que en este terreno pueden seguir pensando de modo muy antropomorfo:

36 Goldman, Religious thinking. Hyde, Religious learning in adolescence.

37 W. C. Nye - J. S. Carlson, "The development of the concept of God in children", The Journal of Genetic Psychology 145 (1984) 137-142.

38 Pitts, "Drawing the invisible". 


\section{Ejemplo:}

Palabras de un chico de 15 años a la pregunta de cómo se imaginaba a Dios:

"Pienso que de pequeño siempre se le dice a uno que como un abuelo de edad con barba y así. Yo mismo creo que es como un hombre a quien sencillamente se le quiere y que irradia también algo positivo. Como un hombre, por tanto, simplemente así, igual como hombre o como mujer, pero así como un monje de edad que irradia una cierta tranquilidad y de ese modo también alegría" ${ }^{39}$.

Para no pocos, representaciones de este orden constituyen, en el tránsito a un pensamiento crítico y formal, una ocasión para la sospecha de que toda religión es un cuento de niños que no se sostiene antes la reflexión crítica.

- En el trabajo pedagógico habría que tener en cuenta el hecho de que una concepción de Dios que resulte ajustada al estadio propio de la evolución cognitiva, no se desarrolla espontáneamente y sin más, sino que requiere ser promovida mediante impulsos bien pensados. Por ejemplo, mediante las siguientes medidas:

- En calidad de adultos, no utilizar afirmaciones toscamente coincidentes con lo humano, a fin de no reforzar la tendencia naturalmente antropomorfa del niño, evitando que se induzcan o se corroboren representaciones inadecuadas de Dios. Evitar, al mismo tiempo, el hablar de Dios como si se supiera todo de Él (o como si uno le conociera al igual que a un compañero de trabajo), sino cuidar de una actitud, que, mediante el ejemplo y la atmósfera creada, puede transmitir el siguiente convencimiento: Él es Alguien más elevado que una persona y distinto de todo ámbito profano concreto, es decir, el fundamento que da consistencia a todo lo demás.

- Ocasionalmente, hacerse conscientes de las representaciones posiblemente muy fragmentarias y nada reflexionadas en torno a Dios e invitar y animar a un nuevo modo de pensar.

39 Beile, "Religiöse Emotionen", 129. 
- Estimular la evolución mediante "ejercicios de analogía" que sirvan para una clarificación: en el caso de conceptos religiosos importantes, hacer que los alumnos asocien y recojan los términos en cuestión, con sus connotaciones y su significado, cuando (a) son utilizados en referencia a personas y (b) atendiendo a cuál pueda ser su interpretación distinta y su pensamiento en torno a ello cuando se dirigen y aplican a Dios. En todo ello han de expresarse reflexiones que conducirían ad absurdum a aquellos antropomorfismos entendidos literalmente. Por ejemplo, en afirmaciones como las siguientes:

\begin{tabular}{|l|l|l|}
\hline Me protege & & Dios \\
\hline Cuida de mí & & \\
\hline Me quiere & & \\
\hline Ha hecho/creado & & \\
\hline Me ha regalado & & \\
\hline Desea de mí que... & & \\
\hline Exige de mí que & & \\
\hline Es Dueño y Señor & & \\
\hline Es compañero y socio & & \\
\hline Es una persona & & \\
\hline
\end{tabular}

El ejercicio anterior ha de ser servir también para llamar la atención sobre la afirmación: "Dios es persona", que normalmente no es entendida de modo análogo sino de forma burdamente antropomorfa, como si Dios fuera efectivamente portador de una cabeza y un cuerpo como nosotros. Resulta estimable, en este sentido, la formulación de un chico de 19 años en referencia a su fe en un "ser superior". A la pregunta de si tal ser es una persona, responde: "Persona...no lo es. Si uno se representa a Dios como persona, viene entonces siempre el hombre de edad con barba y esto, de algún modo, es algo que no se corresponde con Dios. Yo no me puedo imaginar Dios como un buen anciano que anda empujando las nubes a un lado y a otro. El ser de que se trata, en último término, no lo puedes describir. Puede ser muchas cosas" ${ }^{40}$. En vez de "persona" habría que hablar, con algo 40 G. Leyh, Mit der Jungend von Gott sprechen. Gottesbilder kirchlich orienterter Jugndlicher in Horizont korrelativr Theologie, Stuttgart 1994. 
más de acierto, de Aquel a quien nos debemos, que siente con nosotros y a quien podemos dirigirnos, llamándole Tú.

\subsection{El enraizamiento en motivos no precisamente cognitivos}

El desarrollo del entendimiento de Dios, aún siendo de índole tan cognitiva como lo es, no depende sólo del puro interés en un conocimiento y coherencia lógicos, sino también de motivos claramente emocionales, los cuales garantizan que un niño o un adolescente se muestren abiertos a un repensar equilibrado, crítico y constructivo de sus propios convencimientos religiosos y abiertos igualmente a la recepción de nuevas informaciones. En la investigación de Gold$m^{4}{ }^{41}$, en la que alumnos religiosamente desinteresados mostraron durante más tiempo que los religiosamente implicados representaciones masivamente antropomorfas de Dios, y también en muchas otras afirmaciones de jóvenes religiosamente menos sensibilizados (como p. ej. las recogidas por Schusterer ${ }^{42}$ llama la atención que se repitan argumentos contra la fe y la Iglesia, de forma supuestamente estereotipada y sin mayor reflexión propia, que parecen haber sido tomados de los medios y de conversaciones con adultos. (Naturalmente que la actividad religiosa puede también coincidir con una defensa dogmática y fundamentalista ante afirmaciones críticas y disonantes que producen inseguridad).

Las consideraciones realizadas en este punto en torno a la tendencia y a la superación de representaciones antropomorfas de Dios han sido muy generales. Para un entendimiento y una actuación fundamentados pedagógica y psicológicamente es recomendable tener en cuenta el investigar con más detenimiento dos aspectos importantes del antropomorfismo:

- La tendencia a aplicar representaciones materializantes y corporales al ser de Dios.

- Y la tendencia a aplicar representaciones de acción artificialistas y puntuales a la acción creadora y providencial de Dios.

41 Goldman, "Religious thinking from childhood to adolescence".

42 R. Schuster, Was sie glauben. Texte von Jugendlichen, Stuttgart 1984. 


\subsection{La tendencia a atribuir a Dios, traspasando a su ser, repre- sentaciones personales de índole material y corpórea}

“¿Qué aspecto tiene Dios”, “¿Por qué no podemos ver a Dios?”, “¿Dónde está Dios, está en el cielo?”. Cuestiones de este orden constituyen preguntas que niños de 7 a 12 años formulan con frecuencia en expresiones espontáneas sobre temas religiosos ${ }^{43}$. Incluso cuando, como lo hacíamos anteriormente en un plano ideal, intentamos estimular al niño de corta edad, partiendo de la pregunta del "de dónde" y en dirección a una posible intuición que atisbe algo así como un creador por encima de lo humano, sus consideraciones y esfuerzos por entender muestran siempre la tendencia espontánea y genuinamente humana a pensar a "Dios" como un ser que es corporalmente visible, capaz de responder y cuya presencia tiene su lugar en el espacio. Esta expectativa de orden cognitivo y el supuesto en que se apoya pueden conducir a antropomorfismos literales y no simbólicos de Dios, e incluso, en casos extremos, a un Dios sideral, una especie de astronauta, en todo igual a nosotros menos en el lugar de su residencia por encima de la atmósfera terráquea.

Un antropomorfismo masivo, de escasa conciencia trascendente y desprovisto de una mínima calidad analógica se puede percibir en las expresiones que siguen, las cuales atribuyen a Dios un ver y un actuar limitados, así como una presencia asignada a un lugar concreto, tal y como corresponde a las personas humanas: "Dios está sentado en un sillón y mira a la tierra a través de un tubo telescópico" (niño de 8 años). "Dios tiene que divertirse mucho en el cielo. De mí solo ve la parte de arriba de mi gorra: una rodaja redonda grande, y dos pequeños pies" (niña). Sobre la pregunta de si un niño ve a Dios en la oración de la noche: "Siempre que uno reza, Dios baja desde el cielo". Y sobre la siguiente pregunta de si eso es así cuando son muchos los chicos y chicas que rezan: "Sí; por la noche él es muy aplicado, viene hasta abajo y atiende a la oración de cada uno". Pero ¿es que Dios puede escuchar nuestras oraciones?: "Lo que tiene que hacer el niño es gritar fuerte". "Dios se pone algún auricular, y entonces un cable eléctrico llega invisiblemente hasta la habitación del niño" (alumno

43 P. J. Lawrence, "Children's thinking about religion: A study of concrete operational thinking”, Religious Education 60 (1965) 111-116. 
de educación primaria ${ }^{44}$ ). "Si no se ve a Dios, es que ha desaparecido rápidamente y se ha ido de nuevo al cielo" (niño de 8 años). "Dios es un buen espíritu. De día está en el cielo y de noche sale a pasear" (niña de 10 años, que pintaba a Dios como un hombre con barba y a su modo, intentaba aclarar su invisibilidad).

Los niños logran también cuestionar representaciones masivamente corporales de Dios. Posiblemente pueda interpretarse desde ahí la expresión de un niño de siete años: "Si Dios vive en el cielo, ¿necesitará realmente una escalera?" Y de manera aún más clara se da a conocer nuestro supuesto en la intención de una alumna de educación primaria, que piensa del siguiente modo: "Se podría preguntar cómo es que Dios pueda estar al mismo tiempo entre todos. Yo creo que él está extendido sobre toda la tierra y que es invisible y que nosotros le respiramos, y que por la noche se va de nuevo de nuestro interior. Yo creo que él se va de nuevo de nosotros para protegernos y cuidarnos y estar totalmente seguro de que no nos pasa nada y de que nosotros nos durmamos a tiempo." Representaciones antropomorfas de Dios con elementos iniciales de conciencia de trascendencia se dan a conocer principalmente en dos formas:

- Si bien el niño que va creciendo sigue aun atribuyendo a Dios propiedades corporales y humanas, lo cierto es que comienza ya a elevarlas a un nivel suprahumano, incluso a lo humanamente inalcanzable, distanciándose así de un antropomorfismo literal. Lo avalan afirmaciones como las siguientes: "Dios es espíritu, pero es mayor que un hombre, tiene brazos y manos más largos (11 años). "Dios protege a las personas. Yo creo que él vive, así como los hombres, sólo que es más poderoso y todo es más hermoso en su caso" (11 años).

- El niño que va creciendo ya no comprende la persona y la presencia de Dios como algo masivamente material sino como algo "materialmente sutil y fluyente", susceptible de extenderse a todos los lugares y repartirse igualmente a todas partes y, con ello, similar a los pensamientos que no tienen una vinculación

44 R. Goldman, "Religious thinking from childhood to adolescence", 95. 
local, y a los impulsos del alma humana y del espíritu de Dios: (respiración, aire, niebla, nube...) Como, por ejemplo: "Un espíritu no se puede ver. Me imagino que es algo así como la niebla. Está en el cielo y en todas partes" (chico de 11 años en referencia a Dios). "Yo me imagino a Dios de tal modo que más bien es como el aire, a lo mejor en el alma" (10 años).

Consideraciones de este orden pueden denotar tránsitos iniciales hacia un entendimiento de Dios que va adquiriendo sentido más pleno en una mayor conciencia de transcendencia. Esto último se muestra, por ejemplo, en expresiones de alumnos como la siguiente: "Si se pudiera dibujar a Dios, yo lo expresaría como un sol con ojos de bondad" o esta otra: "Dios es un espíritu invisible. Es solamente alma, de otro modo no lo podría decir. Yo pienso que no tiene la apariencia de un hombre. Él está en el cielo y en la tierra" (1l años).

Pero no solo se trata, en lo que atañe a niños que avanzan a su adolescencia, de una estimulación para el cuestionamiento y la superación constructiva de sus representaciones corpóreas de Dios. Ocurre entonces, a menudo, que su entendimiento de Dios caiga ya muy pronto bajo la sospecha de su irrealidad. En una encuesta representativa entre niños de 8 a 13 años, realizada en Francia, se destaca que entre los que afirmaban no creer en Dios, una de las razones más frecuentes para explicarlo era la de no contar con demostración alguna de su existencia, especialmente para el hecho de que no se le pueda ver ${ }^{45}$. Así una chica de 12 años: "Yo no le he visto nunca ante mí, por tanto, no tengo ninguna prueba de que él exista”. La sospecha en torno a la irrealidad de Dios descansa, por una parte, sobre la base del modelo (equivocado) de pensamiento, muy extendido en los países occidentales, y que refuerza notablemente posiciones materialistas y positivistas: "Dios, caso de que exista, ha de ser visible." Pero la misma dificultad (y esta vez entre niños y adolescentes que han crecido en un ambiente religioso) se suma a la consideración de que un Dios interpretado corpóreamente constituye en sí mismo una contradicción: no sería sino sólo una persona humana o no otra cosa que una porción dentro del universo (en el mejor de los casos,

45 P. Jacquemont, Quand les enfants nous parlent de Dieu, Paris 1978. 
la totalidad del mismo), y, por tanto, algo o alguien limitado y no precisamente el creador, en cuanto que es fundamento de la posibilidad de todo lo visible. Si Dios existe, habrá de transcender la espacialidad y la materialidad. Los problemas que niños y adolescentes tienen con todo ello, se muestran en algunas de sus expresiones.

\section{Ejemplos:}

"A lo mejor no hay Dios. La gente solamente se lo ha imaginado. Pero nadie le ha visto" (niño de 5 años). "La maestra nos engaña al decirnos que Dios está siempre entre nosotros; a la hora de rezar yo he mirado con disimulo pero yo no he visto nada" (niño de 6 años). "Dicen que Dios vive en el cielo, y cuando los cohetes (con sus cápsulas espaciales y sus astronautas) suben al universo... ¿por qué no le ven?” (niño de 9 años). Una niña de 13 años, que en su primera infancia había creído con seguridad en un Dios representado antropomórficamente, describe su situación actual: "Yo me he pensado lo siguiente: ¿qué clase de ser es ese, y dónde está? Cuando he mirado al cielo - yo siempre he orado al cielo - entonces me he preguntado por qué no está entre nosotros o a nuestro lado, y cómo es que puede contemplar el mundo entero. $Y$ es que mientras yo rezaba, han rezado también seguramente muchos otros niños más, que yo no sé dónde. Y muchos niños en América...” “¿Habrá oído y escuchado solamente mi oración o también las de los demás? Entonces he vuelto a pensar todo esto y me he alejado de que él exista" ${ }^{46}$. "Yo no creo en Dios (como lo he entendido hasta ahora) porque no me puedo imaginar que alguien, que yo no puedo ver, me pueda ayudar en una situación difícil. Si yo pudiera verle o pudiera hablar con él, me puedo imaginar que yo creería en Dios. ¿En qué pienso yo cuando digo la palabra Dios? Yo pienso en algo supra-humano, que no se puede captar humanamente. Y que en cada paso nos sigue y nos observa" (alumno de formación profesional ${ }^{47}$ ).

\subsubsection{La raíz en la evolución conceptual y lógica}

Se dice a menudo que las representaciones antropomorfas de Dios están en relación con ese nivel de pensamiento evolutivo que llamamos de las operaciones concretas, siempre dependiente de una explicación mostrada sensiblemente, mientras que las concepcio-

46 R. L. Fetz - K. H. Reich - P. Valentin, "Weltbildntwicklung und Gottesvorstellung Eine struktur-genetische Untersuchung bei Kindern und Jugendlichen" en E. Schmitz (ed.), Religionspsychologie, Göttingen 1992, 101-130.

47 Schuster, Was sie glauben, 50. 
nes no antropomorfas de Dios comienzan a ser posibles cuando despunta el nivel de las operaciones formales y abstractas. Esta opinión, pese a ser correcta, resulta excesivamente general. La causa (evolutivamente condicionada) de la tendencia a atribuir al ser de Dios representaciones personales, materialísticas y corpóreas, puede aclararse mejor y ser mejor entendida partiendo de las observaciones de Piaget en torno a la no distinción (él utilizó los términos de "realismo" y "adualismo") o a la insuficiente diferenciación entre mundo interior anímico-espiritual y mundo exterior corpóreo y perceptible en el niño.

Piaget ${ }^{48}$ investigó en su día esta particularidad propia del entendimiento infantil al preguntar a niños de 4 a 12 años por sus interpretaciones en torno a sus pensamientos, a los nombres (o palabras utilizadas) y a los sueños. En cada una de estas formas de representación (Piaget las llama "herramientas del pensamiento") se muestra inicialmente, según su opinión, una triple no distinción o confusión, que con el crecimiento y el desarrollo evolutivo llegan a superarse poco a poco:

El niño confunde, en un comienzo, signos y significados (por ejemplo, la palabra sol no solo significa para él calor y claridad sino que contiene ambos elementos).

Mezcla y/o confunde interior y exterior (por ejemplo, se piensa con la boca y las palabras se encuentran en los objetos mismos, no en la mente humana). El pensamiento no está suficientemente diferenciado de la materia.

Este tercer punto de vista resulta especialmente clarificador para nuestra cuestión: el pensar se le asemeja al niño en primer lugar como un sonido, respiración o aire, ya que en la exteriorización de los pensamientos la mayoría de las veces se utilizan la voz y la boca. En su opinión, los nombres, se leen en las cosas mismas; también las propiedades anímicas se las imagina el niño en forma material. (Así, por ejemplo, entiende que otro niño al darle la mano le ha transmitido su holgazanería y que por esa razón debería de restregarse su mano para borrar la influencia negativa recibida)

48 Piaget, Das Weltbild des Kindes, 39-106. 
El pensamiento infantil tiende, por tanto, a una materialización de lo anímicoespiritual, ya que tal dimensión es imaginada según el modelo del cuerpo humano material y de otras sustancias. (Según Piaget el niño tiende, además, a una psiquización de lo material, en cuanto que lo entiende como animado y lleno de intenciones. Con todo, esta hipótesis animista ha sido puesta en entredicho por la nueva investigación.) De ahí se puede comprender que el niño (y también más de una vez el adulto) tienda espontáneamente a identificar con el cuerpo visible la representación de persona que él mismo va construyendo de su propio ser e incluso de los otros "yoes" distintos de su yo, y, del mismo modo, entienda también a ese "Dios" del que habla su entorno, y lo "asimile" en el pensamiento a su propia interpretación de lo personal, que él capta como algo corpóreo. Sólo gracias a una creciente interiorización y subjetivización llega el niño, en un progreso evolutivo, a interpretar más claramente su pensamiento y su yo como realidades inmateriales, que él mismo produce o hace surgir mediante su propio pensamiento. En opinión de Piaget, el niño alcanza esta capacidad con aproximadamente 11 años, y según la investigación empíricamente mejor asegurada de Laurendeau y Pinard ${ }^{49}$ su comienzo puede ser datado en los 5 a 6 años.

\subsubsection{Influjos de la socialización, consecuencias prácticas}

Una debida socialización puede fortalecer la tendencia (evolutivamente condicionada) a la materialización o puede atenuarla, dificultando o favoreciendo, según los casos, una concepción de Dios que sea más consciente de la transcendencia. Es lo que demuestran las investigaciones anteriormente citadas de Pitts ${ }^{50}$ así como las de Nye y Carlson ${ }^{51}$ entre miembros de diversas confesiones. Notable resulta igualmente la observación de Ranwez ${ }^{52}$ entre niños de Kindergarten, procedentes de familias católicas: aquellos que intencionadamente habían sido acompañados con ejercicios de concentra-

49 M. Laurendeau-A. Pinard, La pensee causale, Paris 1962, 97.

50 Pitts, "Drawing the invisible".

51 Nye-Carlson, "The development of the concept of God in children".

52 P. Ranwez, "B. Mailhiot. “'Et Dieu se fit enfant'. A propos d'un article du R. P. Malhiot, O.P.”, Lumen Vitae 16 (1961) 525-529. 
ción según María Montessori no dibujaban a Dios como un hombre cuando se les animaba a representarlo, mientras que niños de la misma edad educados tradicionalmente, sí que lo hacían. Con toda probabilidad, la socialización cristiana habitual promueve e induce representaciones corpóreas de Dios.

Cuando utiliza el concepto "Dios" como el nombre propio de una persona, sin referirse a una relación a él en cuanto realidad transcendente,

Cuando cita antropomorfismos drásticos, físicos y psíquicos, del Antiguo Testamento (el Yahve que, ríe, duerme, despierta, siente contrición, se enfada o hacen brillar su rostro) sin aclarar su significado simbólico. También el hablar directo de "Padre del cielo" según los evangelios, acentúa supuestamente la inclinación a antropomorfismos psíquicos.

Cuando habla de Dios y de Jesús de un modo tal, que los niños llegan a confundir e igualar ambas dimensiones. Así, cuando dibujan a Dios lo hacen sirviéndose de la figura del hombre piadoso y simpático que han visto alguna vez en alguna imagen de Jesús. También jóvenes entienden a Jesús a veces no como la humana "imagen del Dios invisible" (Col 1, 15), sino como la apariencia de un ser superior, que en sí es visible pero que hasta ahora se mantiene oculto.

Cuando el arte religioso muestra a Dios como a un anciano venerable con barba. Una chica de 14 años: "Yo me lo imagino (a Dios-Padre) con una barba y es así, pienso yo, como se le representa en las imágenes. Entiendo que él no es así, pero no me sale el pensarlo de otra manera que como le he visto siempre en los libros" ${ }^{53}$. Este es un legado problemático, heredado del arte medieval e incluso del arte más moderno. Y hay que subrayar este aspecto, ya que, en el primer milenio, el arte cristiano se sabía tributario de la prohibición veterotestamentaria en lo que atañe a las imágenes y representaba a Dios Padre no como una figura humana sino indicando su presencia mediante símbolos, tales como la luz o la mano. Únicamente Jesús, el Logos hecho hombre, era dibujado y pintado como un hombre - también en su calidad de Cristo preexistente y creador, como tal ha sido representado mediante una cruz en el nimbo. Estas representaciones ya no fueron entendidas debidamente por las generaciones posteriores, que las tuvieron por imágenes de Dios Padre. En el siglo XII, por fin, se comenzó a representar a Dios Padre con un rostro humano y a acentuar su paternidad y eternidad mediante los rasgos de un anciano venerable, dotado de barba (para así diferenciarlo del Hijo).

53 G. Stickler, "Rapressentazione di Dio e immagine dei genitori nella esperienza degli adolescente”, Rivista di Scienze dell'ducazione 12 (1974) 39-75. 
Sólo en el siglo XX, artistas como Marc Chagall y Mark Rothko, entre otros, han vuelto de nuevo a la práctica de referirse simbólicamente a la divinidad.

\subsubsection{En torno a la práctica}

De lo que se trata en la instrucción religiosa es, entre otras cosas, de proporcionar un entendimiento acorde a la evolución cognitiva en torno a Dios, quien para nosotros es un Tú incorpóreo, espiritual pero real.

En el caso de niños de 4 a 12 años, este entendimiento en cuestión apenas puede ser construido mediante explicaciones o aclaraciones puramente conceptuales. La mayoría de las veces, la afirmación "Dios es un espíritu" es entendida en forma puramente literal por niños a los que este concepto no les es familiar y viene unida a representaciones corpóreas más o menos fluidas (Así un niño de 11 años: "Dios es espíritu y es más grande que una persona; tiene brazos y manos más largos que los nuestros"), y eso en el caso de que, bajo el término "espíritu", no se estén representando algo así como un fantasma.

Tampoco la aclaración: "Dios es invisible" supera la tendencia a la materialización, sino que provoca fácilmente la asociación con un ser que es sagaz y astuto, y se esconde en lugares en los que no se le puede ver. "Se oculta, se escapa cuando se le quiere captar con la mirada, únicamente por la noche se mantiene sobre la tierra y de día está en el cielo, etc., es por tanto visible pero oculto a nuestra vida". En el caso del niño pequeño, la indicación "Dios está en todas partes" no le ayuda a la superación de su necesidad de atribuir un lugar concreto al ser divino, sino que precisamente contribuye a la activación de esa tendencia. (Un niño de 6 años: "Dios está en todos los sitios. Dios está aquí - muestra con su dedo el mantel - y está también en cada miga de pan.")

También la indicación: "Dios está en el cielo" indica en dirección a un determinado lugar, aunque lejano y difícilmente visible. De los niños de 6 a 7 años a los que Clavier ${ }^{54}$ preguntó por lo que entendían

54 Clavier, L'idee de Dieu chez l'enfant. 
al referirse al "cielo", el 100\% de ellos (y 55\% de los encuestados de 10 años) contestaron que se trata del cielo físico. Basándose en sus preguntas sobre el significado del cielo al comienzo de la oración del Señor "Padre nuestro que estás en el cielo" e igualmente en lo que atañe a la Ascensión (a los cielos) de Jesús, el investigador suizo Reto Luzius Fetz ${ }^{55}$ concluye que una gran parte de los niños entre 5 y 8 años entiende la frase "Dios está en el cielo" física y simbólicamente, a un tiempo: Dios vive en el firmamento o bóveda celeste, que ciertamente posee el contenido simbólico de lo excelso, pero que coincide también con el cielo considerado desde la mirada cotidiana. En un estadio siguiente son tenidos en cuenta conocimientos rudimentarios de Ciencias de la Naturaleza y el cielo es sustituido por la idea de universo, de modo que su significación religiosa se va perdiendo y da lugar a una transformación de lo divino, convertido entonces en un Dios sideral que gravita vagando en el universo. Una visión de este orden resultará cuestionada críticamente ya en la pre-adolescencia y sólo podrá ser sustituida mediante intervenciones educativas bien cuidadas, que brinden una interpretación más adecuada y hagan posible entender el discurso sobre el cielo al modo de un símbolo religioso, que, junto a una visión científica del mundo, tiene y mantiene su propio derecho.

A una concepción y a un entendimiento positivo de que Dios es para nosotros un Tú incorpóreo, espiritual pero real, pueden contribuir algunas sugerencias como las que siguen:

- La importancia de un determinado clima, que impregne ya los años de la educación primera pero también tramos posteriores, y que permita percibir que creyentes adultos hablan de Dios con mayor respeto y agradecimiento que el tributado al resto de las personas.

- En todas las edades habría que cuidar el hablar de Dios de manera que esta palabra no sea entendida como el nombre propio de una persona humana desconocida, sino que, emocional y cognitivamente, incluya una relación con él en calidad de un Tú suprahumano y transcendente: Dios como el creador, a quien nos debemos y a quien agradecemos nuestro mundo; como interlocutor de un diálogo en nuestros esfuerzos por con-

55 R. L. Fetz, "Die Entwicklung der Himmelssybolik. Ein Beispiel genetischer Semiologie", Jahrbuch der Religionspädagogik 2 (1985) 206-214. 
centrarnos y recogernos en nuestro interior; como origen y fuente de ánimo y energía, etc.

- De este modo cabe esperar que el niño se sienta más invitado a la meditación que al despliegue de sus fantasías, y en lo que atañe a la pregunta sobre el aspecto que Dios pueda tener y el lugar en que se encuentre, su atención sea dirigida al espacio interior de los pensamientos y los sentimientos, y menos al mundo exterior de las personas visibles o de las figuras del espacio.

- Desde un comienzo es también deseable que el hablar de Dios esté unido a momentos de apaciguamiento y concentración (meditación). Esto podría reforzar en el niño - antes incluso de que pueda reflexionar sobre ello - una cierta familiaridad con la diferencia entre la percepción interior y la exterior, así como entre lo material y lo espiritual, y actuar emocionalmente contra la equivocación de que todo lo importante y real es, y tiene que ser visible.

- En torno al final de la Educación Primaria se podrían proporcionar, bien sea como respuesta puntual a expresiones de los alumnos o en el transcurso de una unidad didáctica preparada, impulsos para la superación de la tendencia a lo que estamos llamando "materialización", partiendo precisamente de la posible visión de inmaterialidad del propio yo humano. Pasos posibles en este itinerario:

a. Los alumnos construyen algunas frases con el pronombre personal "yo" y un verbo (yo escribo, yo doy pasos, yo busco algo...). Uno de ellos realiza las actividades nombradas y los demás reflexionan junto con el maestro o la maestra: ¿dónde está el "yo" que dirige el cuerpo y que puede decir: "yo" hago esto o lo otro?

Resultado que esperamos: Nuestro yo está siempre unido al cerebro y con ello al cuerpo visible, pero al mismo es no-visible, incluso cuando se llega a investigar el propio cerebro... Cuando dos están hablando el uno con el otro, se entienden con palabras que pueden ser oídas o con gestos que pueden ser percibidos con la vista, pero, así y todo, el yo del uno no puede ver el tú del otro, y eso que es lo más valioso e importante del interlocutor...

b. Citamos una oración, la rezamos y comenzamos a dialogar entre nosotros: ¿Qué es, en nuestro pensar en Dios o en nuestro hablar con él en la oración, lo que resulta muy parecido a nuestro pensar y hablar con una persona de nuestro entorno...y qué es distinto? Resultado que buscamos: En el caso de un diálogo con un interlocutor, vemos su cuerpo, leemos su carta escrita o escuchamos (directamente 
o al teléfono) las palabras que provienen de sus labios. A Dios no le podemos percibir con nuestros ojos y oídos, pues si así fuera sería un "otro más", como el resto de las personas que tienen que funcionar en la vida, o no sería otra cosa que una porción o parte del mundo (aunque fuera la más soberana), que actúa sobre otra porción o parte del mundo, algo así como un viento impetuoso sobre un bosque o como el sol sobre un campo de trigo...pero no sería Aquel, que hace posible, crea y sostiene constantemente a las personas y al mundo. (La invisibilidad de Dios debe ser entendida como algo positivo y no precisamente como un déficit.) Pero nosotros podemos percibir a Dios internamente con nuestro pensamiento y nuestro sentimiento, en la medida en que asentimos (mediante un "ver" espiritual) que es Él quien nos da la vida, o cuando percibimos en nuestra conciencia que Él nos "llama" (mediante un "escuchar" espiritual) a ser justos y a vivir amando. Meditando y orando es como nuestro yo invisible pero corpóreo entra en relación con el igualmente invisible y esta vez incorpóreo Tú de Dios.

Al final de la Educación Primaria habría que lograr el ser conscientes del carácter simbólico y metafórico, así como del sentido y la significación de los antropomorfismos presentes en las expresiones de la Biblia y en las imágenes del arte. La Biblia habla a menudo de Dios como de un ser visible para acentuar mediante este lenguaje figurativo que se está tratando de un "Dios vivo" (Sal 42, 3; 84, 3; Jr 10,10; 23, 36; Mt 16,16), que tiene interés por nosotros y quiere actuar con nosotros como no pudiera hacerlo con mayor interés y vigor ninguna otra persona visible de nuestro mundo.

Un par de preguntas para el aula: 1) ¿En qué insisten - debidamente entendidas - las siguientes expresiones, y qué es lo que no quieren decir?: "De la obra de sus manos habla el firmamento" (Sal 19,2). "Pero yo, Señor, confío en ti ... En tus manos está mi destino" (Sal 31,15). "El señor ilumine su rostro sobre vosotros y os conceda la paz" (Nm 6,25). "El señor es Rey de la tierra entera; ... Dios está sentado en su santo trono" (Sal 47,8). "Así es como debéis orar: "Padre nuestro que estás en el cielo)" (Mt 6,9). 2) ¿Qué significa, por fin, y qué es lo que no quiere decir cuando Jesús confiesa de sí mismo: "Quien me ve a mi (tiene vivencia y experiencia de mi) ha visto al Padre" (Jn 14,9; Jn 1,14; 1 Jn 1,1-3)? 


\subsection{La tendencia a atribuir a la acción creadora y providente de Dios representaciones de acción artificialista y puntual}

No sólo el ser de Dios, también su actuación es entendida por niños y adolescentes muy a menudo a la manera de un antropomorfismo literal. Esta tendencia aflora en sus consideraciones sobre la particularidad de un actuar de ese orden, cuya interpretación toma como base una primera intuición temprana en torno al "de dónde" supra-humano del mundo pero que es aún francamente muy imprecisa. Entre los cálculos de cómo imaginarse la actuación de Dios y en qué relación se encuentre con actuaciones de personas y fuerzas de la Naturaleza, la tendencia a trasponer formas de fabricación humana y modalidades puntuales de acción (intervenciones) a la acción creadora y providente de Dios puede ejercer un influjo mayor o menor, y desembocar en concepciones de Dios que recuerdan a un hacedor y guía entronizado por encima de las nubes. Siguiendo a las investigaciones de Piaget ${ }^{56}$ sobre interpretaciones precientíficas o "pre-causales" de niños en torno a los orígenes de personas, animales y cosas, podríamos designar la tendencia en cuestión como artificialismo religioso (del latín artificio: actuación programada, obra, trabajo).

La inclinación al pensamiento artificialista puede ayudarnos a situar en su debido lugar dificultades no leves que niños y jóvenes suelen tener a la hora de acceder a la fe cristiana en la creación y entender el apoyo (providencia) que Dios presta a su obra. Igualmente nos permite tener en cuenta el modo como la educación puede contribuir a una superación aceptable de estas dificultades.

Un antropomorfismo masivo que supuestamente se imagina la actuación de Dios al modo de una acción manual y de un trabajo o intervención del todo puntuales, se da a conocer en expresiones como las que siguen.

- Una niña de 3 años pregunta quién es Dios. Adulto: "El que lo ha hecho todo: las flores, el sol y todo lo demás." La niña, (teniendo en cuenta que en el momento está lloviendo): “¿Ha hecho también la lluvia? El adulto: "Sí". La niña de 3 años: "Y ¿dónde ha pulsado para que llueva?”.

56 Piaget, Das Wetbild des Kindes. 
- Un niño de 5 años camina en silencio con su padre por el bosque, admira los grandes árboles y dice espontáneamente: “Vaya trabajo!”. A la pregunta de su padre por el comentario del niño, éste responde: "Si Dios ha tenido que hacer todos estos árboles, ha tenido que trabajar duro."

- Incluso a los 15 años un alumno responde a la cuestión de cómo se imagina él mismo a Dios: "Me lo imagino siempre como una persona, como... no sé, - posiblemente debido a influencias de mi infancia - como un hombre anciano con una barba blanca, bastante todopoderoso y grande, y con unas manos grandes, con las que intenta modelar la tierra, $y$ dirigir así el destino de las personas mediante las cosas que acontecen"57.

Fetz, Reich y Valentin ${ }^{58}$, en su investigación sobre cómo entendían la creación niños y adolescentes de 5 a 19 años llegaron a la conclusión de que los niños más jóvenes se imaginan al creador en forma humana incluso cuando afirman que es un espíritu. En ese caso resulta que es transparente y que puede volar. "Pero así y todo tiene un cuerpo y sobre todo ojos y manos, que le son atribuidos precisamente con vistas a su actuación fabricadora". Para los más jóvenes Dios tiene la estatura común de un hombre, para los mayores, por el contrario, es mucho mayor. "Aproximadamente tres veces más grande que la tierra, como lo dice un niño de 7 años que se esfuerza por pensar a Dios tan grande que la tierra que él ha de crear se convierta para él en un objeto manual."

Un antropomorfismo con ciertos elementos de conciencia transcendente se da a conocer en expresiones que, si bien contienen formas de actuación humana, dejan entrever igualmente un modo especial de proceder. Así la respuesta de un niño de 7 años a la pregunta de cómo se imagina la creación del mundo: "Yo pienso que Dios pintaría en el cielo árboles y todo lo demás, y que entonces habrá sido como cuando uno mira en un pozo y entonces eso se reflejaría en la tierra"59. De modo parecido una niña de 6 años intentaba superar su visión antropomórfica de la creación poniéndola en cuestión una y otra vez y llegando a la idea de que Dios no necesita material alguno para sus obras, sino que (por decirlo de alguna manera) "sueña" algo, que entonces - de modo distinto a lo que ocurre en nuestros sueños - adquiere realidad y se mantiene en ella ${ }^{60}$.

57 Beile, Religiöse Emotionen, 129.

58 Fetz-Reich-Valentin, "Weltbildntwicklung und Gottesvorstellung".

59 T. Thun, Die Religion des Kindes, Stuttgart 1959, 125.

60 H. Hetzer, "Selbständige Bemühungen kleiner Kinder, Gott zu bergreifen", De 
A menudo los niños cuestionan representaciones masivamente artificialistas que les vienen espontáneamente cuando se trata del $\operatorname{crear}$ (= hacer) de Dios.

\section{Así un niño de 5 años:}

"Cuando lo hizo todo, habría allí también un trabajador que tenía que hacer las casas. ¿No podía Dios hacerlo todo solo?”' ${ }^{\circ}$. Más allá incluso va la pregunta de un niño de 8 años: “¿De dónde tomó Dios todo eso para hacer al primer hombre y el primer árbol de todos?"'2. Aquí los niños atisban que un trabajar solamente humano (crear = hacer) no puede aclarar el origen y el último "de dónde" del mundo. Esta visión crítica infantil puede ir preparando un entendimiento algo más consciente de trascendencia en torno a lo que significa la actuación creativa de Dios, en la medida, naturalmente, en que no se convierta en un obstáculo para el que no recibe respuesta alguna. También ese problema inherente a una interpretación artificialista de la creación, es decir, el asunto de cómo pensar la actuación de Dios, y en conjunción con la misma, las acciones de los hombres y de las fuerzas de la naturale$\mathrm{za}$, puede convertirse bien pronto en una cuestión que preocupa.

En este sentido, un adulto recuerda sus clases de religión en los primeros años escolares:

"Un día, nuestro párroco comentó el relato de la creación, insistiendo en que Dios lo ha creado todo. Lo primero en lo que pensé fue en la naturaleza y claro, yo estaba de acuerdo con que los castaños en el patio de la escuela y los árboles frutales de mi padre habían sido hechos por Dios. Pero en ese momento, mi mirada se fijó en la lámpara, que, como una bola de cristal, estaba colgando en nuestra clase, y pensé: eso no lo ha hecho Dios. Esas lámparas las he visto yo en una tienda, se hacen en alguna fábrica y se pueden comprar."

Si en este caso, la creación por parte de Dios es negada al tratarse de productos humanos (artefactos), en otros casos, como el del comentario de un niño de 10 años, se extiende también a la vida humana como tal: "Vosotros me decís que Dios da la vida, pero eso lo hace la madre..." 63 .

Evangelische Erzieher 23 (1971) 137-147.

61 Klink, "Kind und Leben", 21.

62 Klink, "Kind und Leben", 23.

63 Klink, "Kind und Leben". 
Igualmente, la cuestión de la teodicea, es decir, cómo entender que el buen creador permita el mal, se agudiza, en el marco de representaciones artificialistas, hasta el problema de cómo pueda (directamente) "hacer" lo malo y ser (en casos puntuales) responsable del mismo, preocupación esta que aparece ya muy pronto.

- Una niña de 4 años: “¿Dios también ha hecho los lobos?” Y tras la respuesta afirmativa por parte del interlocutor adulto: "Pero, ¿por qué? ¿Es que el creador ha hecho también personas malas?” ${ }^{4}$.

- Un niño de 5 años: “¿Y por qué ha hecho Dios esos bichitos que traen los dolores de garganta?".

No podemos afirmar que todos los niños y adolescentes que comenzaron entendiendo su fe en el creador de modo artificialista y más tarde descubrieron que una visión así era insuficiente, pasen, sin más, a compartir un entendimiento más adecuado de la creación y más consciente de su carácter de trascendencia. En no pocos casos llega incluso a formarse en ellos la impresión de que la fe cristiana en la creación y en su diligente cuidado por parte de Dios, se encuentra en franca contradicción con la lógica y el conocimiento científico. Y es que tal fe incluye (supuestamente) la visión contradictoria de un Dios, que mediante un hacer humano logra lo que humanamente es imposible, y con ello entra en contradicción con la explicación causal de orden científico en torno al comportamiento humano (Psicología) y a los procesos bio-psíquicos que lo constituyen (Ciencias Naturales): la consecuencia puede entonces ser que el Creador se convierta en una instancia innecesaria y por ello mismo, eliminable. De este modo se entiende que el estar de acuerdo con la afirmación "Dios puede intervenir en el mundo" presente un declive patente entre alumnos austríacos, partiendo de un 74\% de aceptación en el caso de alumnos de 10 a 11 años hasta descender al 31\% entre alumnos de 18 y más años ${ }^{65}$ Es significativa, en este sentido, la expresión de un alumno de Formación Profesional:

64 Klink, "Kind und Leben".

65 A. A. Bucher, Religionsunterricht: Besser als sein Ruf? Empirische Einblicke in ein umstrittenes Fach, Innsbruck 1996. 


\section{Ejemplo:}

"Yo no creo en Dios, porque creo en la información científica sobre el origen de la tierra y porque aún no he tenido ninguna muestra de que Dios exista. Yo no creo que el mundo fue hecho en siete días, porque los resultados científicos sobre el origen de la tierra me parecen más lógicos y por ello me resultan más convincentes"66.

Con el paso al pensamiento formal resulta comprensible que esta tensión entre fe y conocimiento racional se agudice. Resumiendo, y esquematizando sus resultados, es posible asumir las siguientes conclusiones, extraídas de la conocida investigación de Kalevi Tamminen:

- El adolescente considera la fe en el creador como algo irreal porque no es armonizable con una explicación científica del mundo y la suple con una visión puramente científica naturalista (CIENT).

- Se aferra a una visión religiosa bíblica sin poderla o quererla poner en sintonía con la científica. Piensa en dos mundos sin coordinación, el uno científicamente determinado y el otro religioso (REL).

- El joven admite una interpretación complementaria, es decir integrando la aclaración religiosa y la científica (INT).

- Se siente inseguro - tal vez porque no ha pensado suficientemente en ello - en el marco de esta problemática (INS).

La reconocida investigación de Kalevi Tamminen ${ }^{67}$ en torno a la evolución religiosa de alumnos finlandeses entre los 7 y 18 años, que incluía, en lo que atañe a la creación, tres distintas propuestas en forma de discusiones ficticias, ha traído como resultado que la visión (INT), la que resulta más deseable desde criterios de la Pedagogía de la Religión, sin ser muy fuerte contó efectivamente con la identificación más numerosa en los niveles escolares superiores (alumnos de 17 y 18); así y todo, la aceptación de una visión científica sin fe (CIENT) iba creciendo a partir de la quinta clase (tras los 11/12 años), al igual que el número de los inseguros (INS) crecía igualmente entre los alumnos de las clases quinta a novena. A modo de muestra, reproducimos uno de los tres textos junto con los resultados de la encuesta.

66 Schuster, Was sie glauben, 26

67 Tamminen, Religiöse Entwicklung. 
En la clase de Religión tuvo lugar un debate en torno al origen y la evolución del universo. En un momento la discusión presentó las siguientes posiciones:

- Andreas: Se me hace difícil decir algo sobre eso. No hubo nadie que pudiera haberlo observado. (INS = "No puedo decir nada").

- Peter: La Biblia dice que Dios ha creado los Cielos y la Tierra, y así lo creo (REL).

- Hans: Yo opino que el mundo ha surgido por energía propia y así se ha desarrollado. Dios no tiene nada que ver con eso (CIENT).

- Roger: Yo creo que Dios está en el origen del mundo, que desde entonces sigue avanzando en su evolución (INT).

Identificaciones con los diferentes modelos de aclaración del origen del mundo.

\begin{tabular}{|l|c|c|c|c|c|}
\multicolumn{1}{|c}{ Nivel de aula } & \multicolumn{1}{c}{ III } & V & VII & IX & XI \\
\hline Peter (REL) & 62 & 47 & 30 & 21 & 18 \\
\hline Hans (WISS) & 4 & 7 & 17 & 22 & 24 \\
\hline Roger (INT) & 25 & 30 & 26 & 28 & 39 \\
\hline Andreas (UNS) & 9 & 16 & 28 & 29 & $20^{68}$ \\
\hline
\end{tabular}

\subsubsection{Las raíces en la evolución lógico-conceptual}

Aun cuando las más de las representaciones artificialistas de niños cristianos en lo que atañe a la creación vienen influenciadas por la educación religiosa, la inclinación a atribuir el origen de las cosas a algún tipo de producción humana tiene probablemente como origen "una acusada tendencia, propia del modo infantil de pensamiento y que se enraíza profundamente...en la vida afectiva e intelectual del niño" ${ }^{69}$. Esta tendencia aclara la disposición espontánea de niños y adolescentes a entender (asimilar) afirmaciones religiosas sobre la creación y Providencia de Dios en primer lugar según el modelo de la fabricación humana (bien sea ésta manual, mediante instrumentos o herramientas e incluso mediante acciones como soplar, escupir y otras).

68 Tamminen, Religiöse Entwicklung, 137.

69 Piaget, Das Weltbild des Kindes, 280. 
Las explicaciones de índole artificialista respecto al origen de las cosas constituyen, por tanto, en general, $y$ con independencia de interpretaciones religiosas, una tendencia espontánea. Este supuesto se evidencia en el hecho de que niños pequeños plantean sus preguntas sobre la causalidad de las cosas en términos claramente artificialistas: “¿Quién ha hecho el sol?” (2 años y 5 meses). “¿Quién hace que las estrellas luzcan?" (5 años).

Esto mismo viene avalado por numerosas observaciones recogidas por Piaget ${ }^{70}$ y sus colaboradores en el marco de diálogos semidirigidos y mantenidos con niños de 4 a 12 años, a los que se iba preguntando por el origen de los astros (el sol, la luna, las estrellas), por el de los factores atmosféricos (el cielo, la noche, las nubes, el rayo, la lluvia, la nieve o el frío), por el de las aguas (los ríos, los lagos, el mar) y por el origen de los árboles, de los montes y de la tierra. Piaget llegó a pensar, lo que sería posteriormente corroborado por investigaciones de Laurendeau y Pinard ${ }^{71}$, que las explicaciones pre-causales primeras se van desarrollando (evolucionan) a lo largo de cuatro estadios hasta llegar a un entendimiento científico.

- A un nivel de "artificialismo difuso" el niño ve las cosas, diríase como dependientes de las personas y hechas para él y por él (a modo de ejemplo: el sol ha tenido su comienzo cuando nosotros empezamos a vivir y nos sigue para iluminarnos.)

- En una fase de "artificialismo mitológico" el niño adquiere una seguridad más precisa sobre este origen, inventando mitos sobre su fabricación. (por ejemplo: el sol se originó cuando alguien raspó para ello una cerilla o lo fabricó con una piedra.) Ese alguien puede ser un hombre o Dios mismo.

- En el estadio que podría llamarse "artificialismo técnico" (entre los 7/8 y 9/10 años), el niño explica el origen de las cosas mediante determinadas conexiones de causas técnico-físicas y leyes fijas, de las que se hace una idea más o menos precisa. (Como, por ejemplo: los astros provienen de la inflamación y el amontonamiento de las nubes que proceden de los humos de las casas. Para hacer lluvia alguien deja que el agua caiga por medio de un colador como el de una ensaladera.)

70 Piaget, Das Weltbild des Kindes.

71 Laurendeau-Pinard, La pensee causale. 
- Una causalidad propia, así como leyes que les son propias a las cosas mismas, llegan, por último, a ser consideradas con una fuerza mayor cuando el niño de 9 a 10 años, en un nivel que podríamos llamar "artificialismo inmanente", atribuye el origen de las cosas a esas cosas mismas o bien a la naturaleza, sin atribuirlas, por tanto, a un "fabricador" que les sea externo, bien sea éste humano o divino. (Las estrellas provienen del sol; los rayos se comprimen hasta convertirse en constelaciones.) A partir de este nivel se desarrolla la capacidad de aclaración causal científica.

En qué medida niños y adolescentes educados en el ámbito religioso cristiano tienden a un entendimiento artificialista de la creación, es una cuestión que Fetz, Reich y Valentin ${ }^{72}$ han querido investigar, partiendo de la teoría de Piaget, y mediante preguntas a niños de 5 a 19 años sobre el modo, el tiempo y la instancia responsable del origen o de la creación del mundo. Aunque su estudio se redujo a entrevistar únicamente a cuatro individuos por cada uno de los años tenidos en cuenta y no buscaba formular una secuencia rigurosa de estadios, la propuesta conclusiva de los autores (brindada a partir de los datos) resulta bien significativa, por cuanto que permite atisbar un posible itinerario evolutivo en las visiones infantiles, que partiendo de posiciones artificialistas no reflexionadas pueden ir desarrollándose hacia un entendimiento de la creación, compatible con la ciencia.

- En un estadio inicial - opinan los autores - el niño atribuye a la acción de Dios cosas que evidentemente están "hechas" (artefactos). Si se pregunta a niños pequeños qué es todo lo que Dios ha hecho, nombran, en primer lugar, objetos como las casas altas, los muebles, los automóviles y los productos alimenticios, y solamente en segundo término, también el suelo, la tierra, las plantas y la naturaleza. En esta fase atribuyen aún a Dios (y de forma literal) un hacer fabricador, ya que tiene que hacer las cosas que les serían imposibles o muy difíciles de hacer a las personas (las casas altas sin escaleras, los primeros hombres sin mesas). Niños que no han sido educados religiosamente (o lo han sido muy escasamente) prefieren, con todo y ya muy pronto) modelos de aclaración puramente naturalísticos.

- En su fase álgida, el niño considera como obra de Dios solo lo que no presenta rasgos de fabricación humana: Dios no forma ya las casas, sino solo la tierra. Hace crecer las plantas y hace que se originen los animales. No fabrica, por tanto, como el hombre, determinadas cosas, sino que su obra

72 Fetz-Reich-Valentin, "Weltbildntwicklung und Gottesvorstellung”. 
es el mundo vital del ser humano, un mundo que aún es pensado de modo antropomorfo, ya que en la opinión de la mayoría de los niños Dios está necesitado de algo que está y estaba siempre ahí: del sol, del espacio, del aire y de los materiales con los que hace la tierra. Una actividad propia de las plantas y de los animales (su crecimiento, su multiplicación) es ya reconocida por el niño, por lo que la acción creadora de Dios queda relegada a lo que es el comienzo: Las "primeras" plantas y los "primeros animales" los ha hecho él, después ya no juega ningún papel creador.

- En su fase de disolución, un artificialismo tal, no debidamente cuestionado y que utiliza sin más la fórmula "Dios-ha-hecho-el-mundo", se torna insostenible debido a la creciente y cada vez más extensa información de orden científico. Un hacer puramente humano difícilmente ha podido originar - por poner un ejemplo - el universo, ya que entonces tal capacidad no tendría límites, y, por otra parte, si las cosas, como lo afirman tanto la teoría del Big Bang como la doctrina de la evolución, se desarrollan por sí mismas, no pueden al mismo tiempo ser hechas por Dios. El entendimiento artificialista de la creación deja paso o bien a una negación total de la fe en la creación o será sustituido por una interpretación debidamente reflexionada y científicamente más compatible con la creación. Los adolescentes y jóvenes alumnos a quienes esto último les resulta posible, sustituyen generalmente la imagen de un "Dios-que-hace" por la idea de una "fuerza" que actúa en todo. En opinión de los autores, la necesidad de desarrollar un entendimiento de la creación que esté en armonía con una visión de mundo científicamente avalada, sigue siendo una tarea por solucionar en lo que concierne a jóvenes en torno a los 20 años. Por lo observado a lo largo de la investigación, ninguno de los encuestados acreditaba haber recibido, ni en clases de religión ni a través de lecturas, alguna aportación en términos de una creación desde la nada ("creatio ex nihilo") y de la necesaria conservación del mundo ("creatio continua"). Según ambos grupos de investigadores, el grupo en torno a Piaget y el formado en torno a Fetz, la tendencia a una interpretación artificialista de la creación, considerada desde la perspectiva del desarrollo lógico-conceptual (y emocional), tiene sus raíces en intentos y en dificultades del entender, tales como las que se dan a conocer a continuación.

El niño que va creciendo, tiende a entender (y asimilar) el discurso religioso en torno a la creación y al creador partiendo, en primer lugar del modelo que más familiar le resulta desde la evidencia de sus propias acciones y desde la observación de las acciones de sus padres y del resto de los adultos: el fabricary el hacer humanos. Nada le es más cercano que atribuir o extrapolar esos modos a la acción de Dios. 
Según el estudio de Gelman y Kremer ${ }^{73}$, niños en edades de 4 a 7 años piensan de modo algo menos artificialista que lo que Piaget llegó a concluir en su investigación, cuya metodología no fue tan rigurosa como deseable. Y, sin embargo, la tendencia infantil al respecto, sigue siendo clara e incontestable. Bien es verdad que con 4 años ya les es posible distinguir entre lo producido naturalmente y lo que es hecho por manos humanas, pero, así y todo, en aquello en que todavía no disponen de conocimientos específicos en torno a los mecanismos de producción, siguen valiéndose - en sus propias suposiciones - del esquema, para ellos tan evidente, de la actuación humana.

A nivel emocional, el artificialismo en orden a la creación es vivenciado por el niño como algo muy satisfactorio, ya que responde a su necesidad de protección y a su inclinación a un "finalismo antropocéntrico" (Piaget), según el cual todo "está hecho para" los hombres. Finalismo (del latín "finis": objeto de algo, finalidad) es, según Piaget ${ }^{74}$ la tendencia a atribuir a la Naturaleza esquemas de actuaciones personales u observadas en el entorno social, que muestran una intención y una dirección hacia un fin, y considerar tales atribuciones como regidas por el principio: "todo para el mayor beneficio del hombre"75. Según esto, el sol y la luna "nos tienen que iluminar" y la lluvia "tiene que regar" nuestras plantas, al igual que también nosotros organizamos nuestro mundo doméstico con ese sentido funcional. Las preguntas anteriores sobre si Dios ha hecho también los lobos, las personas malas y las bacterias, surgen precisamente de la extrañeza y desilusión sufridas por un pensamiento finalista de esta naturaleza.

Si la solución al problema reside en que lleguemos a entender que el mundo (naturaleza y seres humanos) sigue a sus propios impulsos y leyes $\mathrm{y}$, al mismo tiempo, es creado por Dios, de modo que tanto la visión científica como la religiosa estén integradas en una visión

73 S. A. Gelman - K. E. Kremer, "Understanding natural cause: Children's explanations of how objects and their properties originate", Child Development 62 (1991) 396-414.

74 J. Piaget, La causalité physique chez l'enfant, Paris 1927; J. Piaget, Sprechen und Denken des Kindes, Schwann, Düsseldorf 1972; Piaget, Urteil und denkprozeb des kindes; Piaget, Das Weltbild des Kindes.

75 Piaget, Das Weltbild des Kindes, 1183. 
comprehensiva de la realidad, ello está exigiendo, junto con la debida estimulación mediante la instrucción religiosa, naturalmente, una cuidada coordinación de dos puntos de vista diferentes, tarea que no puede ser iniciada con anterioridad a la fase del pensamiento formal en edad juvenil (pero que habrá de ser preparada con antelación).

\subsubsection{Influjos de la socialización, consecuencias prácticas}

El hecho de que niños puedan ser instruidos en una visión de mundo exclusivamente naturalista o también religiosa, el que puedan ser ayudados a descubrir la inconveniencia de representaciones artificialistas sin ser abandonados a sí mismos en sus dificultades cognitivas, la tarea de acompañarlos con cierto cuidado en el camino de un entendimiento cada vez más transcendente de la creación... depende también, con inclusión de todo lo que ha sido tenido en cuenta en este capítulo, de los valiosos estímulos de una socialización religiosa. Y también, como no puede ser de otro modo, de la disposición a mantener debates en todas estas cuestiones. Según opinión de los maestros que fueron consultados por Tamminen ${ }^{76} \mathrm{en}$ el marco de su investigación, los alumnos que daban preferencia a una integración de los posicionamientos científicos y religiosos en lo que atañe al origen del mundo eran los que igualmente mostraban el mayor interés en las clases de religión, en contraposición a los que optaban por visiones exclusivamente científicas, exentas de horizonte religioso.

\subsubsection{En torno a la práctica educativa}

De todo lo dicho se desprende como una de las tareas más importantes, la de estimular una interpretación aceptable de la creación e intentarlo en un modo que esté adecuado a la evolución de niños $\mathrm{y}$ adolescentes.

- Comenzando ya por la fase de Educación Infantil, lo más acertado es referirse a la buena creación de Dios en unos términos y en una actitud tales que permitan vivenciar que estamos hablando de Alguien muy por encima de cualquier "hacedor" humano, y ante quien también noso-

76 Tamminen, Religiöse Entwicklung, 143. 
tros los adultos sentimos respeto, admiración y agradecimiento. Es muy conveniente, en todo caso, evitar la expresión Dios "hace" en favor de "Él crea" y aludir desde un principio a que su crear es distinto al ser comparado con nuestro hacer humano.

- Al final de la Educación Primaria se puede ir avanzando en el desarrollo de lo dicho.

El objetivo podría ser el acercamiento a una doble perspectiva, según la cual la acción creadora de Dios se distingue de toda acción humana por cuanto que ha de ser entendida como creación desde la nada (creatio ex nihilo) y, al propio tiempo, incluye la vivencia de lo que podríamos llamar conservación del mundo (en palabra de San Agustín: creatio continua; en formulación de Martín Lutero: conservatio creaturae), visión que reconoce al mundo el mantenimiento de una causalidad propia. Estas aclaraciones pueden servirse de la doctrina teológica de Dios en calidad de "primera causa" que hace posible el universo y las personas como "causas segundas". El reconocimiento formulado por P. Teilhard de Chardin ("Dios hace que las cosas se hagan" - "Dieu fait se faire les choses") puede y ha de ser confrontado con una conciencia creciente en torno a la magnitud de la propia ley de la naturaleza, de la psique humana y de la sociedad, tanto en lo que atañe a una radical negación de la fe en la creación como también en la reducción de la acción creadora de Dios a su comienzo, lo que dificulta notablemente una espiritualidad viva y pujante de la creación.

Precisamente para fomentarla, y teniendo en cuenta el programa curricular y el interés actual de los alumnos, determinadas tareas y actividades (bien sea en forma de juegos de rol o efectuando los experimentos pertinentes) podrían ayudarnos a tener más conciencia de cómo damos logro a nuestros propósitos (trabajos tecnológicos, cocina) valiéndonos de algún instrumento técnico (nevera, radio, auto) o cómo utilizamos fuerzas y leyes de la naturaleza a la hora de sembrar plantas y recoger sus frutos, dar de comer a animales y ponerlos a nuestro servicio, coordinarnos en tareas con otras personas y otras acciones cotidianas. Podríamos entonces realizar un ejercicio de analogía mediante preguntas bien formuladas, y captar la diferencia exis- 
tente entre el modo como nosotros los humanos hacemos algo, y cómo crea Dios el mundo y sigue actuando en él. Resultados deseados en un ejercicio de este nivel pueden ser brevemente aludidos a continuación, sin que, debido a la falta de espacio, nos explayemos en propuestas más y mejor elaboradas.

¿De qué recursos nos tendremos que valer para promover la obtención de un objetivo que nos ha parecido necesario? (Manos, Herramientas, Máquinas).

- ¿Necesita Dios igualmente de tales recursos? (Él nos ha creado y ha creado el mundo solamente desde su Espíritu, desde su bondad y desde su poder.)

- ¿Qué material o materiales necesitamos para lograr el resultado deseado? (Madera, metal, plástico, agua, aire, plantas, animales)

- ¿Creamos nosotros mismos estos materiales o únicamente los elaboramos?

- ¿Ha trabajado también Dios con materiales como estos, cuando creó el mundo? (Él ha llamado al mundo de la nada al ser, sin que hubiera algo previo.)

- ¿Qué fuerzas y leyes de la materia, y de la naturaleza utilizamos nosotros mismos en la tarea descrita y también en el resto de nuestras tareas? (La evidencia de que el cable de metal es conductor de corriente; que una mezcla de leche, nata, azúcar, elementos saborizantes y espesantes, y mediante el cuidado de rebajar debidamente la temperatura, llega a ser un rico helado; que explosiones del combustible en un motor mueven un coche o un barco; que mediante ondas televisivas sea posible retransmitir una competición deportiva; que de racimos debidamente plantados y podados se recolecta uvas; que se puede ordeñar una vaca y se puede cabalgar raudo sobre un caballo...)

- ¿Inventamos y hacemos nosotros mismos estas fuerzas y tales leyes? Si Dios ha creado el mundo desde la nada y lo ha llamado a ser... ¿es, entonces, al igual que nosotros, únicamente un utilizador de aquellas fuerzas y leyes...o su inventor?

- ¿Es Dios, acaso, la fuerza de la gravedad, la energía solar o alguna otra causa que nosotros investigamos y utilizamos hora...o es más bien la causa de estas causas, Aquel que da posibilidad a todo ello? 
Tratándose de alumnos por encima de los 12 años, podríamos también apoyarnos en las siguientes consideraciones:

- Cuando construimos una casa u otras cosas, actuamos únicamente en determinados tramos o puntos del tiempo: al comienzo, sobre todo, y a partir de entonces, solo de vez en cuando, como cuando conviene remodelar algo o efectuar una reparación. Al igual que cuando plantamos manzanos o domesticamos animales. Éstas intervenciones puntuales y determinadas suelen ser suficientes, ya que las cosas, evidentemente, permanecen y crecen sin nosotros,

- Pero, ¿quién garantiza que se mantengan en su ser, que continúen en su ser y no vuelvan a caer en la nada? (Dios no sólo las ha hecho en su comienzo, sería la visión del Gran Relojero, que una vez hecho el engranaje y haberle dado cuerda, se desentiende del reloj - sino que las mantiene y las sostiene en el ser. El sostiene constantemente el mundo y nos sostiene también a nosotros mismos. La creación acontece, sigue aconteciendo también ahora, en este mismo momento. Por ello, Dios, a su propia manera - eterna, supratemporal - está y sigue constantemente vuelto a nosotros, o dicho de otro modo, nos es presente y no simplemente sumido en lejanía o ausencia de interés.)

Cuando nosotros planificamos y realizamos algo para nosotros o para otros - una excursión en bicicleta, por ejemplo -, dirigimos un determinado acontecimiento a su realización, es decir, impulsamos el logro de lo deseado, nos montamos en un tiempo concreto en la bicicleta y recorremos un tramo determinado.

- ¿Pero cómo actúa Dios en nuestra actuación? (Normalmente, prescindiendo ahora de los poco frecuentes milagros, deja que la naturaleza haga su recorrido y deja a las personas su libertad. El hace posible que llevemos a término determinados acontecimientos e incluso los quiere así, cuando se trata de cosas importantes como lo es la ayuda a los necesitados. Pero su actuación no es directa sino mediada a través de nosotros, si estamos dispuestos a ello.

- Puntos de vista concretos de esta reflexión pudieran ser recapitulados en la oración de un trabajador, de un investigador o técnico, de una doctora, de una madre o de una cooperante en el desarrollo.)

- En caso de alumnos y alumnas de más edad se podrían elaborar estas consideraciones de un modo más reflexivo. Sería bien importante en la Educación Secundaria contribuir a una visión según la cual la explica- 
ción causal científica y la versión metafísico-religiosa no se excluyen, sino que, al modo de dos perspectivas de una única realidad, se complementan la una a la otra. En especial habría que estimular una "coordinación" positiva y no sólo defensiva de la fe en la creación y la teoría de la evolución: no según la fórmula exclusiva: "creación o evolución”, ni tampoco según una fórmula meramente aditiva: "creación y evolución”, sino según la fórmula interactiva: "creación en evolución" (Christian Kummer). 